\title{
Robust Lanthanoid Picolinate-Based Coordination Polymers for Luminescence and Sensing Applications
}

\author{
Verónica Jornet-Mollá, Chris Dreessen, and Francisco M. Romero* \\ Cite This: Inorg. Chem. 2021, 60, 10572-10584 \\ Read Online
}

ABSTRACT: Picolinate-based segmented dianionic ligands $\mathbf{L}_{\mathbf{1}}{ }^{2-}$ (5-((4-carboxyphenyl)ethynyl)picolinate) and $\mathbf{L}_{2}{ }^{2-}$ (5,5' -(ethyne1,2-diyl)dipicolinate) have been used in the synthesis of the highly robust and luminescent europium(III) coordination polymers $\left[\left(\mathrm{CH}_{3}\right)_{2} \mathrm{NH}_{2}\right]\left[\mathrm{Eu}\left(\mathrm{H}_{2} \mathrm{O}\right)_{2}\left(\mathbf{L}_{\mathbf{1}}\right)_{2}\right](\mathbf{1})$ and $\left[\left(\mathrm{CH}_{3}\right)_{2} \mathrm{NH}_{2}\right]\left[\mathrm{Eu}\left(\mathbf{L}_{2}\right)_{2}\right]$. $\mathrm{H}_{2} \mathrm{O} \cdot \mathrm{CH}_{3} \mathrm{COOH}$ (2). Both 1 and 2 exhibit high selectivity for detection of nitroaromatic compounds since they act as quenchers

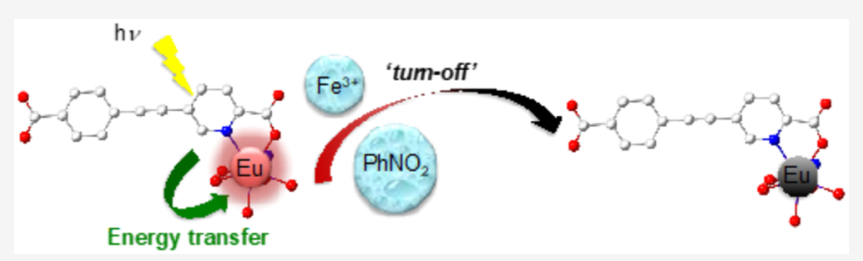
of the $\mathrm{Eu}^{3+}$ emission. Stern-Volmer plots, using nitrobenzene as a quencher, yielded values of $K_{\mathrm{SV}}=150 \mathrm{M}^{-1}$ and $160 \mathrm{M}^{-1}$ for $\mathbf{1}$ and 2, respectively. Luminescence studies in the presence of different metal ions indicate a high selectivity for Fe ${ }^{3+}$ detection, with $K_{\mathrm{SV}}$ values of $471 \mathrm{M}^{-1}$ and $706 \mathrm{M}^{-1}$ for 1 and 2 , respectively. Both 1 and 2 possess extremely robust extended structures, leading to emissive properties that are stable in a wide $\mathrm{pH}$ range.

\section{INTRODUCTION}

Coordination polymers (CPs) are crystalline materials formed by the self-assembly of metallic centers and multicoordinating organic molecules as bridging ligands through metal-ligand bonds. ${ }^{1-5}$ The common interest in these compounds has been driven by their promising applications in fields such as ion exchange, ${ }^{6}$ gas adsorption and separation processes, ${ }^{7-10}$ drug delivery, ${ }^{11}$ luminescence and sensing, ${ }^{12-14}$ and catalysis. ${ }^{15-17}$

The design of luminescent sensors remains a hot topic due to its high demand in a wide variety of fields, such as analytical chemistry, clinical biochemistry, and environmental science. Supramolecular interactions of luminescent CPs with the analyte may increase or decrease the luminescence response, resulting in a turn-on or turn-off display, respectively. ${ }^{18-22}$ The use of coordination polymers as fluorescent probes relies mostly on fluorescence quenching. ${ }^{23,24}$ Different types of analytes can be detected by this method, and there are already many fluorescent molecular sensors commercially available; however, their selectivity, limit of detection, and toxicity should be improved.

Early detection of metal ions such as $\mathrm{Pb}^{2+}, \mathrm{Cd}^{2+}, \mathrm{Hg}^{2+}, \mathrm{Al}^{3+}$, and $\mathrm{Fe}^{3+}$ is highly recommended, due to their accumulation as pollutants in water. $\mathrm{Fe}$ (III) is one of the most common and relevant components in the Earth's crust and is also present in biological systems, playing an important role in metabolic processes. Its presence in an appropriate amount is essential for regular growth; nevertheless, an excess of iron(III) can lead to health problems. Recently, Ln-CPs have been found to be promising candidates in this regard, their main drawback being their poor stability in aqueous medium. The first example of a europium(III) fluorescent sensor for $\mathrm{Fe}^{3+}$ detection was developed by Dang et al. in 2012. Nonetheless, the selective quenching mechanism consisted of cation exchange between the original metal ion and $\mathrm{Fe}^{3+}$ cations rather than in a specific interaction. ${ }^{25}$ Later, more Eu-CPs have been applied for the sensing of $\mathrm{Fe}^{3+}$ ions, and Table S1 contains some examples with corresponding $K_{\mathrm{SV}}$ (Stern-Volmer constant) and limit of detection (LOD) values. The quenching mechanisms are based on cation exchange between $\mathrm{Fe}^{3+}$ and $\mathrm{Eu}^{3+}$, competitive absorption of excitation energy, and the interaction between $\mathrm{Fe}^{3+}$ and the organic ligand. ${ }^{26-33}$

Nitroaromatic compounds (NACs) represent also serious sources of pollution of soils and groundwater, mainly because of their high toxicity. Such materials are also frequently used as explosive materials in terrorism. Highly sensitive and efficient materials able to detect trace amounts of NACs in water are thus in strong demand. It was not until 2015 that Ln-CPs were applied as fluorescent sensors for NACs detection, exhibiting quenching in the presence of nitro explosives with estimated $K_{\text {SV }}$ values among the highest known for CPs. ${ }^{34}$ Table S2 contains a list of selected metallic complexes used for detection of nitrobenzene (chosen as a representative nitroaromatic compound), together with the $K_{\mathrm{SV}}$ and LOD achieved. $\mathrm{Zn}(\mathrm{II})$ $\mathrm{CPs}$ are those which present the best parameters (higher $K_{\mathrm{SV}}$ and lower LOD) in this context.

Most metal-organic frameworks are however easily hydrolyzed. In order to construct stable complexes, strong coordination bonds are needed, and several strategies are

Received: April 21, 2021

Published: July 7, 2021 
currently being developed for this purpose. ${ }^{35}$ One is the combination of carboxylate-based ligands and high-valent metal ions. Alternatively, soft azolate ligands in conjunction with soft divalent metal ions have also been used.

Another approach is focused on chelating anionic ligands, which is an almost unexplored alternative to that based on high-valent complexes. There are only a few examples related to tetraanionic bisbidentate dioxidobenzenedicarboxylate ligands ${ }^{36-38}$ and catecholates. ${ }^{39}$ In this context, the picolinate (pic) ligand is a promising chelating anionic fragment for the design of robust CPs with high stability. On the other hand, ethynylene bridges have been incorporated in the design of some organic linkers because they provide rigidity, linear connectivity, and electron delocalization. ${ }^{40,41}$ Despite the fact that the picolinate ligand is a universal chelating anionic entity, only a few segmented polytopic picolinate ligands have been reported $^{42-45}$ and their use in metal-organic frameworks is unexplored. Further, picolinate ligands are known to act as photosensitizers, transferring the absorbed energy in the UV region to lanthanoid cations, resulting in an enhanced lanthanoid luminescence (antenna effect). ${ }^{46}$ For example, a $10^{4}$-fold enhancement of $\mathrm{Tb}$ (III) luminescence by using dipicolinate ligands as photosensitizers has been reported. ${ }^{47}$

We report herein on the synthesis, structural characterization, and optical properties of highly robust europium(III) coordination polymers based on the segmented ligands (Chart 1) 5-((4-carboxyphenyl)ethynyl)picolinate $\left(\mathbf{L}_{\mathbf{1}}{ }^{2-}\right)$ and $5,5^{\prime}$ -

Chart 1. Segmented Picolinate-Based Ligands Used in This Work

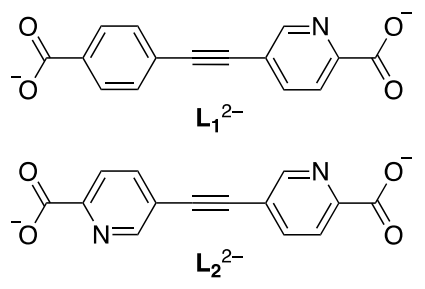

(ethyne-1,2-diyl)dipicolinate $\left(\mathbf{L}_{2}{ }^{2-}\right) . \mathbf{L}_{1}{ }^{2-}$ is a heteroditopic ligand containing a picolinate chelating unit and a benzoate anion connected by an ethynylene linker. $\mathbf{L}_{2}{ }^{2-}$ is homoditopic, the ethynylene rigid spacer connecting two picolinate chelating units. Comparison is given on the emission properties of these $\mathrm{Eu}^{3+}$ compounds and their use in sensing of metal ions and nitroaromatic pollutants under extreme $\mathrm{pH}$ conditions.

\section{EXPERIMENTAL SECTION}

All chemicals and solvents were used as received. The synthesis of ligands $\mathrm{L}_{1}{ }^{2-}$ and $\mathbf{L}_{2}{ }^{2-}$ was previously described. ${ }^{48}$

Synthesis of $\left[\left(\mathrm{CH}_{3}\right)_{2} \mathrm{NH}_{2}\right]\left[\mathrm{Eu}\left(\mathrm{H}_{2} \mathrm{O}\right)_{2}\left(\mathrm{~L}_{1}\right)_{2}\right]$ (1). A solution of $\mathrm{Eu}\left(\mathrm{NO}_{3}\right)_{3} \cdot 6 \mathrm{H}_{2} \mathrm{O}(11.15 \mathrm{mg}, 0.025 \mathrm{mmol})$ and 5-( (4carboxyphenyl)ethynyl)picolinic acid (13.35 mg, $0.05 \mathrm{mmol})$ in 2.5 $\mathrm{mL}$ of $\mathrm{DMF} / \mathrm{H}_{2} \mathrm{O}$ (3:2 ratio) was placed in a glass vial and stirred for $30 \mathrm{~min}$. Next, two drops of nitric acid (65\%, aq.) were added, and the resulting suspension was placed in an oven. The mixture was heated at $130{ }^{\circ} \mathrm{C}$ for 3 days and then cooled to room temperature at a cooling rate of $0.2 \mathrm{~K} \cdot \mathrm{min}^{-1}$. Colorless spearhead-shaped crystals were obtained, filtered, and air-dried to give compound 1. Yield: $15.1 \mathrm{mg}$ (79\%). Elem anal. calcd for $\mathrm{C}_{32} \mathrm{H}_{26} \mathrm{EuN}_{3} \mathrm{O}_{10}$ : C, 50.27; H, 3.43; N, 5.50. Found: C, 49.86; H, 3.38; N, 5.36. IR $\left(\mathrm{cm}^{-1}\right): 3097,3075$, 3019, 2963, 2801, 2221, 1631, 1587, 1373, 1356, 1244, 782, 724, 693, 662, $627,560,400$.

Synthesis of $\left[\left(\mathrm{CH}_{3}\right) \mathrm{NH}_{2}\right]\left[\mathrm{Eu}\left(\mathrm{L}_{2}\right)_{2}\right] \cdot \mathrm{H}_{2} \mathrm{O} \cdot \mathrm{CH}_{3} \mathrm{COOH}$ (2). A mixture of $\mathrm{Eu}\left(\mathrm{NO}_{3}\right)_{3} \cdot 6 \mathrm{H}_{2} \mathrm{O}(24.9 \mathrm{mg}, 0.056 \mathrm{mmol})$ and 5,5'-(ethyne-1,2- diyl)dipicolinic acid $(15 \mathrm{mg}, 0.056 \mathrm{mmol})$ in $\mathrm{H}_{2} \mathrm{O}(0.5 \mathrm{~mL})$ and DMF $(4 \mathrm{~mL})$ was stirred in a glass vial for $30 \mathrm{~min}$ until a solution was formed. Then, acetic acid $(1100 \mu \mathrm{L})$ was added, and the mixture was placed in an oven at $130{ }^{\circ} \mathrm{C}$ for 3 days. A cooling rate of $0.2 \mathrm{~K} \cdot \mathrm{min}^{-1}$ was applied to cool down the sample to room temperature. After the liquid was decanted, colorless aggregated crystals of 2 were obtained. The crystals were washed with water and dried in the air. Yield: 14.3 $\mathrm{mg}(60 \%)$. Elem. anal. calcd for $\mathrm{C}_{32} \mathrm{H}_{26} \mathrm{EuN}_{5} \mathrm{O}_{11} \cdot 2 \mathrm{H}_{2} \mathrm{O}$ : C, 45.51; H, 3.58; N, 8.29. Found: C, 45.22; H, 3.11; N, 8.29. IR $\left(\mathrm{cm}^{-1}\right): 3383$, 3033, 2761, 2461, 1606, 1556, 1361, 1244, 1033, 806, 700, 661, 628, 389.

Single-Crystal X-ray Diffraction. Suitable crystals of $\mathbf{1}$ and $\mathbf{2}$ were coated with paratone $\mathrm{N}$ oil, fixed on a small fiber loop, and mounted on an Oxford Diffraction Supernova diffractometer equipped with a graphite-monochromated Enhance Mo X-ray source $(\lambda=0.71073 \AA)$ at $120 \mathrm{~K}$. The data collection routines, unit cell refinements, and data processing were carried out using the CrysAlis software package. ${ }^{49}$ The structures were solved using SHELXT 2018/ 2 via the WinGX graphical interface ${ }^{50}$ and refined using SHELXL$2018 / 3 .^{51}$ All non-hydrogen atoms were refined anisotropically (DELU and SIMU restraints were applied to $\mathrm{C}$ and $\mathrm{O}$ atoms of the acetic acid molecule present in $\mathbf{2}$ to allow their anisotropic refinement). $\mathrm{H}$ atoms on carbon atoms were included at calculated positions and refined with a riding model with relative isotropic displacement parameters. Instead, $\mathrm{H}$ atoms on solvent molecules and amine $\mathrm{H}$ atoms on dimethylammonium cations were found in Fourier difference maps, except for $\mathrm{H}$ atoms of $\mathrm{O} 1 \mathrm{~W}$ in compound 2. CCDC 2068840 and CCDC 2068875 contain the supplementary crystallographic data for $\mathbf{1}$ and 2, respectively. These data are provided free of charge by The Cambridge Crystallographic Data Centre.

Powder X-ray Diffraction (PXRD). PXRD measurements of compounds 1 and 2 were collected using $\mathrm{Cu} \mathrm{K} \alpha$ radiation $(\lambda=$ $1.54056 \AA$ ) at room temperature and in a $2 \theta$ range from 2 to $40^{\circ}$. Polycrystalline samples were lightly ground in an agate mortar and filled into a $0.5 \mathrm{~mm}$ borosilicate capillary prior to being mounted and aligned on an Empyrean PANalytical powder diffractometer. For $\mathrm{pH}$ dependent measurements, the samples were soaked in aqueous solutions with $\mathrm{pH}$ values ranging from 1 to 14 for $2 \mathrm{~h}$. Then, the samples were filtered and air-dried prior to their analysis. Simulated diffractograms were obtained from single-crystal X-ray data using the CrystalDiffract software.

Absorption Spectroscopy and Photoluminescent Properties. UV-visible absorption spectra were recorded at room temperature for complexes $\mathbf{1}$ and $\mathbf{2}$ and for the ligands in their acid forms on a JASCO V-670 absorption spectrometer. Also, the absorption spectra of solvent samples and $0.01 \mathrm{M}$ aqueous solutions of different metal ions were registered at room temperature. Measurements were performed in the 240-1000 nm range. Photoluminescent data of both complexes in aqueous suspensions were obtained with a Varian Cary Eclipse spectrometer, in quartz cuvettes $(1 \mathrm{~cm}$ path length). For $\mathrm{pH}$-sensing measurements, the solid materials $(1 \mathrm{mg})$ were vigorously dispersed in aqueous solutions (1 $\mathrm{mL}$ ) at different $\mathrm{pH}$ values. Emission spectra were registered after $2 \mathrm{~h}$ of sample preparation. The range of study was $540-720 \mathrm{~nm}$ with excitation wavelengths of 344 and $340 \mathrm{~nm}$ for compounds 1 and 2, respectively. For titration experiments, $25 \mathrm{mM}$ or $50 \mathrm{mM}$ solution of $\mathrm{Fe}\left(\mathrm{NO}_{3}\right)_{3}$ in water (for compounds 1 and 2, respectively) or $0.1 \mathrm{M}$ nitrobenzene in $\mathrm{EtOH}$ were incrementally added to a cuvette containing $1 \mathrm{mg}$ of the sensor in $1 \mathrm{~mL}$ of Milli- $\mathrm{Q}$ water, and emission spectra were recorded at each point.

The photoluminescence characteristics were studied in the solid state using a Xe lamp coupled to a monochromator as the excitation source and an integrated sphere coupled to a spectrometer (Hamamatsu C9920-02 with a Hamamatsu PMA-11 optical detector) in order to quantitatively determine the quantum yield for complexes 1 and 2. Luminescence decay measurements were measured using an Edinburgh FLS 1000 spectrometer setup and Fluoracle software. The samples were excited by a $375 \mathrm{~nm}$ laser (CNI MLL-III-375-100 mW) at a frequency of $20 \mathrm{~Hz}$. The luminescence was collected via two 
monochromators at $614 \mathrm{~nm}$ with a bandwidth of $1 \mathrm{~nm}$ in the multichannel-scaling mode.

Other Characterization Techniques. IR transmission measurements of both complexes were performed directly from the powdered samples at room temperature in a FT-IR spectrometer (Bruker, alpha II) equipped with an attenuated total reflection (ATR) accessory in the range $400-4000 \mathrm{~cm}^{-1}$. C, $\mathrm{H}$, and $\mathrm{N}$ elemental analyses were performed using a CE INSTRUMENTS 1110 EA elemental analyzer (SCSIE, Universitat de València). Thermogravimetric analyses of salts 1 and 2 were performed on a Mettler-Toledo TGA/SDTA/851e apparatus under $\mathrm{N}_{2}$ atmosphere at a scan rate of $10 \mathrm{~K} \cdot \mathrm{min}^{-1}$. Analysis of the proportion of metals in the samples was performed on a Philips XL30 ESEM scanning microscope equipped with an EDAX microprobe (SCSIE, Universitat de València).

\section{RESULTS AND DISCUSSION}

Synthesis and Characterization. Crystalline europium(III) coordination polymers 1 and 2 were prepared by the reaction of $\mathrm{Eu}\left(\mathrm{NO}_{3}\right)_{3} \cdot 6 \mathrm{H}_{2} \mathrm{O}$ with the appropriate picolinic acid under hydrothermal conditions. The addition of an acid modulator (nitric acid or acetic acid) was necessary in order to obtain single crystals suitable for structural characterization. Both compounds could also be obtained from the corresponding diesters in similar conditions.

The phase purity of the bulk materials was confirmed by PXRD measurements (Figure S1). The experimental diffractograms recorded at room temperature for compounds 1 and $\mathbf{2}$ compare well with the simulated patterns obtained from singlecrystal data at $120 \mathrm{~K}$.

Thermogravimetric analyses (TGA) of $\mathbf{1}$ and $\mathbf{2}$ were performed under a nitrogen atmosphere (Figure S2). For 1, the TGA curve shows three separated steps of weight loss. The first one takes place between 416 and $435 \mathrm{~K}$ and is ascribed to the release of two coordinated water molecules (calcd.: $4.71 \%$; found: $5.27 \%$ ). The second and third steps occur above $540 \mathrm{~K}$ and are attributed to the decomposition of dimethylammonium cations and $\mathrm{L}_{1}{ }^{2-}$ ligands. These results are consistent with the formulation deduced from single-crystal X-ray diffraction measurements that show the presence of two water molecules per lanthanoid ion. For 2, the TGA plot exhibits also a weight loss in multiple steps. Between RT and $390 \mathrm{~K}$, a first weight loss associated with the release of water present in the voids of the structure takes place. A second step ascribed to the loss of acetic acid is detected between 440 and $580 \mathrm{~K}$. The total weight loss for these first two steps is $9.26 \%$ (calcd.: 9.65\%). Then, above $620 \mathrm{~K}$ decomposition of dimethylammonium cations and $\mathbf{L}_{2}{ }^{2-}$ ligands occurs. These observations are consistent with the release of two different types of solvent molecules and are in agreement with the formulation deduced from single-crystal X-ray diffraction. Clearly, 1 shows a higher dehydration temperature, indicating that water is more tightly bound to the anionic lattice as compared to 2. This is expected for the presence of $\mathrm{H}_{2} \mathrm{O}$ molecules coordinating to the $\mathrm{Eu}^{3+}$ cation in $\mathbf{1}$.

\section{STRUCTURAL PROPERTIES}

Single-crystal X-ray analysis reveals that $\mathbf{1}$ (Table 1) crystallizes in the monoclinic space group I2/a. Its asymmetric unit contains half $\mathrm{Eu}^{3+}$ cation, one $\mathrm{L}_{1}{ }^{2-}$ dianion, one coordinated water molecule, and half dimethylammonium cation $\left(\left[\left(\mathrm{CH}_{3}\right)_{2} \mathrm{NH}_{2}\right]^{+}\right)$. This cation is required in order to balance the negative charge of the host framework and originates from the hydrolysis of dimethylformamide (DMF) solvent molecules. $^{52,53}$
Table 1. Crystallographic Data

\begin{tabular}{|c|c|c|}
\hline & 1 & 2 \\
\hline chemical formula & $\mathrm{C}_{32} \mathrm{H}_{26} \mathrm{EuN}_{3} \mathrm{O}_{10}$ & $\mathrm{C}_{32} \mathrm{H}_{26} \mathrm{EuN}_{5} \mathrm{O}_{11}$ \\
\hline$a(\AA)$ & $11.97630(10)$ & $19.6440(2)$ \\
\hline$b(\AA)$ & $10.67410(10)$ & $12.35500(10)$ \\
\hline$c(\AA)$ & $24.7299(3)$ & $13.21490(10)$ \\
\hline$\alpha(\mathrm{deg})$ & 90.00 & 90.00 \\
\hline$\beta(\operatorname{deg})$ & $98.0830(10)$ & 90.00 \\
\hline$\gamma(\operatorname{deg})$ & 90.00 & 90.00 \\
\hline$V\left(\AA^{3}\right)$ & $3129.97(6)$ & $3207.28(5)$ \\
\hline$T(\mathrm{~K})$ & $120.2(3)$ & $119.7(8)$ \\
\hline$Z$ & 4 & 4 \\
\hline$M_{r}(\mathrm{~g} / \mathrm{mol})$ & 764.52 & 808.54 \\
\hline crystal system & monoclinic & orthorhombic \\
\hline space group & $I 2 / a($ No. 15$)$ & $\operatorname{Pna2}_{1}$ (No. 33) \\
\hline $\begin{array}{l}\text { crystal dimensions } \\
(\mathrm{mm})\end{array}$ & $0.224 \times 0.151 \times 0.104$ & $0.124 \times 0.105 \times 0.073$ \\
\hline$\mu(\operatorname{Mo~} \mathrm{K} \alpha)\left(\mathrm{mm}^{-1}\right)$ & 2.066 & 2.025 \\
\hline$\lambda(\AA)$ & 0.71073 & 0.71073 \\
\hline density $\left(\mathrm{Mg} / \mathrm{m}^{3}\right)$ & 1.622 & 1.674 \\
\hline index ranges for $h, k, l$ & $\begin{array}{l}-16 / 16,-14 / 14,- \\
34 / 34\end{array}$ & $\begin{array}{l}-25 / 24,-16 / 16,- \\
16 / 17\end{array}$ \\
\hline$\theta$ range $(\mathrm{deg})$ & 3.189 to 29.753 & 3.298 to 28.107 \\
\hline goodness-of-fit on $F^{2}$ & 1.153 & 1.082 \\
\hline reflns collected & 37152 & 118251 \\
\hline $\begin{array}{l}\text { independent reflns } \\
\quad\left(R_{\text {int }}\right)\end{array}$ & $4273(0.0249)$ & $7383(0.0975)$ \\
\hline $\begin{array}{l}\text { data/restraints/ } \\
\text { parameters }\end{array}$ & $4273 / 0 / 218$ & $7383 / 33 / 453$ \\
\hline$R 1, w R 2[I>2 \sigma(I)]^{a}$ & $0.0145,0.0355$ & $0.0389,0.0765$ \\
\hline$R 1, w R 2(\text { all data })^{a}$ & $0.0158,0.0363$ & $0.0627,0.0883$ \\
\hline $\begin{array}{l}\text { absolute structure } \\
\text { parameter }\end{array}$ & $\mathrm{n} / \mathrm{a}$ & $-0.039(6)$ \\
\hline
\end{tabular}

The $\mathrm{Eu}^{3+}$ cation sits on a two-fold axis and displays an eightcoordinated distorted square antiprism geometric configuration (Figure 1). It is coordinated by two chelating picolinate

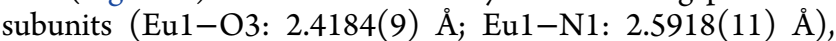
two monodentate benzoate groups (Eu1-O1: 2.3512(9) $\AA$ ), and two water molecules (Eu1-O1W: 2.3799(10) ̊̊). Eu-O bond distances are lower than the $\mathrm{Eu}-\mathrm{N}$ distance, in agreement with previously reported values for $\mathrm{Ln}$ (III) complexes based on pyridyl-carboxylate ligands. ${ }^{54}$

Continuous shape measure (CShM) calculations using SHAPE 2.1 confirm that the coordination geometry is a distorted square antiprism $\left(D_{4 d}\right.$, with a minimum CShM value of 9.458, Table S3). ${ }^{55-58}$

The ditopic ligand $\mathrm{L}_{\mathbf{1}}{ }^{2-}$ bridges two $\mathrm{Eu}^{3+}$ cations through the chelating picolinate group and the benzoate anion acting in a monodentate mode. This connectivity results in the formation of a two-dimensional (2D) rhombus grid layer that presents channels $(6.685 \times 24.582 \AA)$ along the $a$ axis (Figure S3). These voids are occupied by dimethylammonium cations (one cation per channel) thanks to the establishment of hydrogen bonds with noncoordinated picolinate oxygen atoms

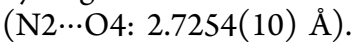

Additional hydrogen bonds between coordinated water

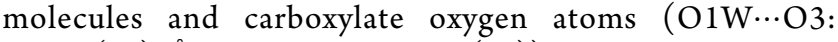
2.7677(14) Å, O1W…O2: 2.6092(14)) are established. The $\mathrm{O} 1 \mathrm{~W} \cdots \mathrm{O} 2$ interaction is a very strong intramolecular $\mathrm{H}$-bond between water molecules and benzoate anions coordinating to the same $\mathrm{Eu}^{3+}$ cation, whereas the weaker intermolecular $\mathrm{H}$ - 


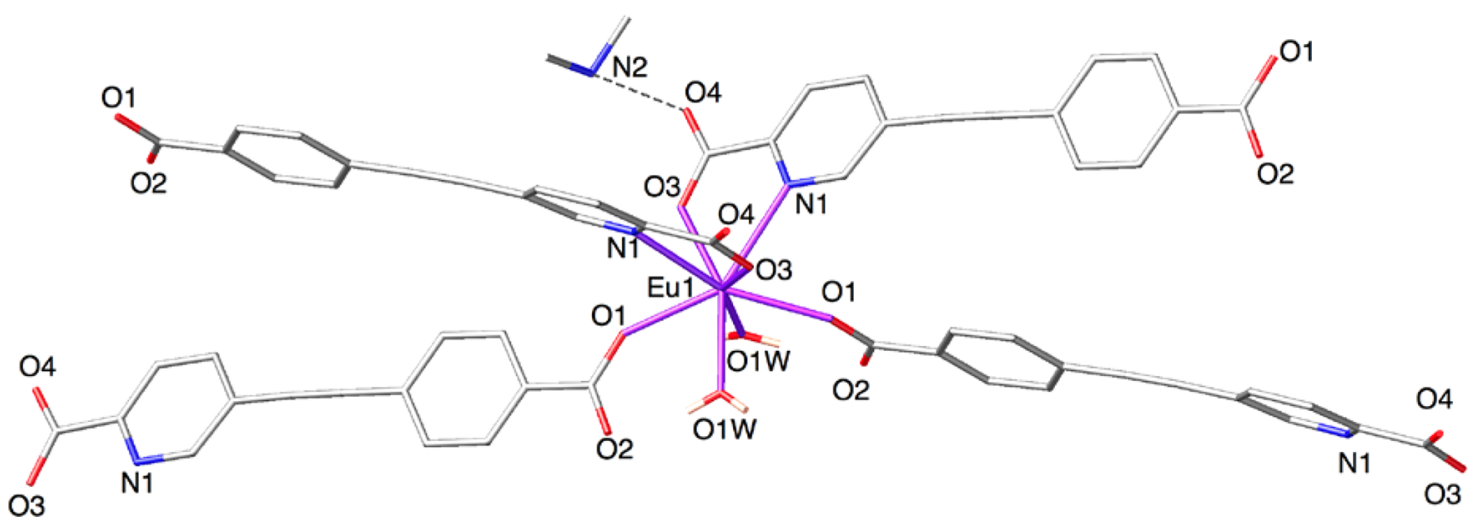

Figure 1. Stick plot of the $\mathrm{Eu}^{3+}$ coordination environment in $\mathbf{1}$.
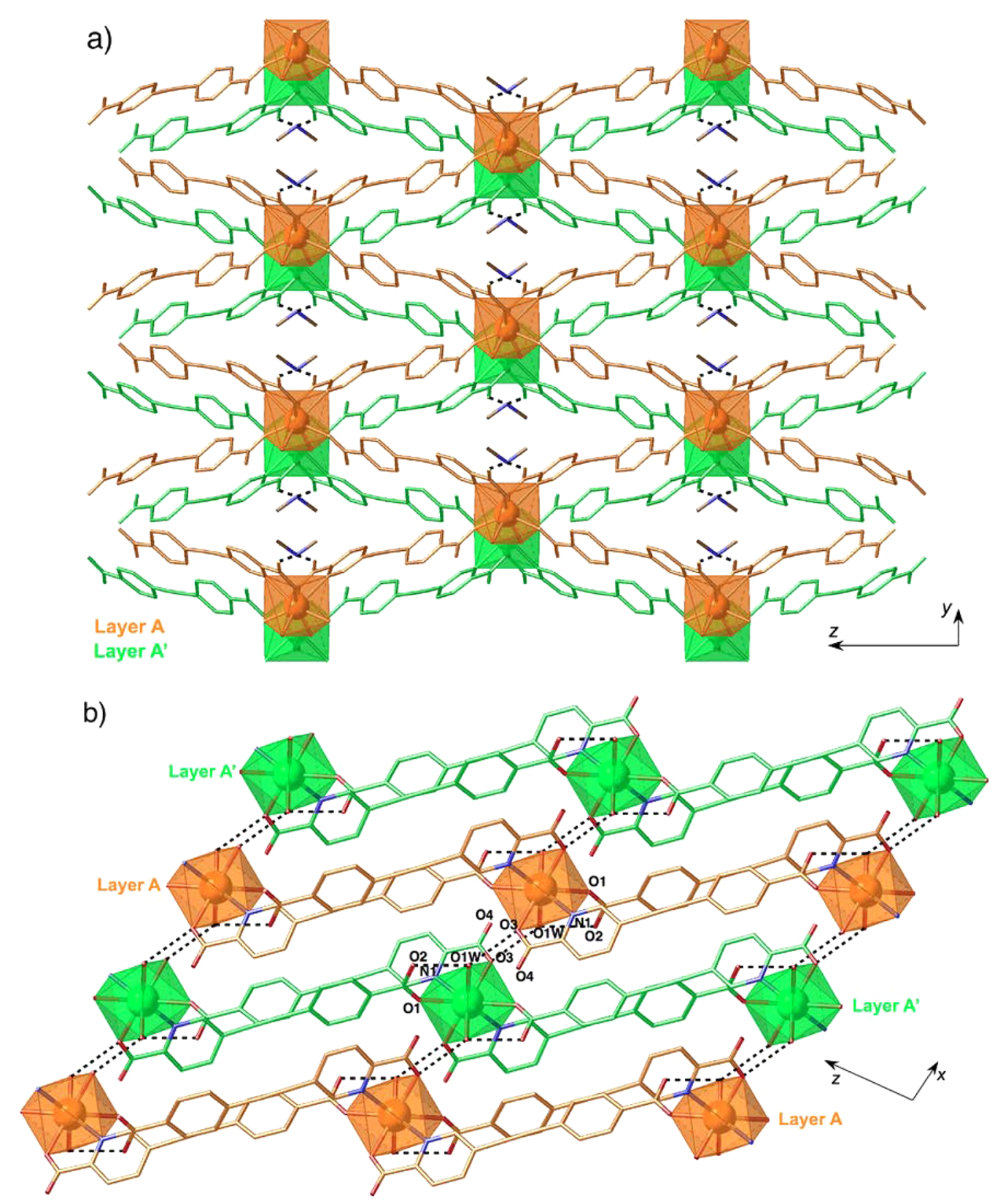

Figure 2. Projection of the crystal structure of $\mathbf{1}$ onto the $y z(\mathrm{a})$ and $x z(\mathrm{~b})$ planes showing the layered $\mathrm{AA}^{\prime} \mathrm{AA}^{\prime}$ arrangement (each layer is depicted in a different color). $\mathrm{H}$ atoms have been omitted for clarity. 
bond interaction involving the picolinate moiety $\mathrm{O} 1 \mathrm{~W} \cdots \mathrm{O} 3$ bridges complexes of consecutive layers, leading to a $3 \mathrm{D}$ doubly $\mathrm{H}$-bonded network with an $\mathrm{AA}^{\prime} \mathrm{AA}^{\prime}$ arrangement (Figure 2a). In addition, $\pi-\pi$ stacking interactions are observed between pyridine and benzene aromatic rings of adjacent layers (Figure $2 b$ ).

The anion exhibits an almost planar conformation, with a small dihedral angle between the pyridine and benzene rings $\left(12.2(4)^{\circ}\right)$ that allows coordination to two different metal cations. In addition, the carboxylate group involved in chelation presents a low torsion angle of $6.0(4)^{\circ}$, and the geometry of the triple bond is only slightly distorted $(-\mathrm{C}-\mathrm{C}-$ $\mathrm{C}-$ bond angles of $178.0(4)^{\circ}$ and $177.6(4)^{\circ}$, in comparison with the ideal value of $180^{\circ}$ ).

It is interesting to compare $\mathbf{1}$ with $\left[\left(\mathrm{CH}_{3}\right)_{2} \mathrm{NH}_{2}\right][\mathrm{Ln}$ $\left.\left(\mathrm{H}_{2} \mathrm{O}\right)_{2}(\mathrm{CPA})_{2}\right]$, a related family of lanthanoid complexes based on 5-(4-carboxyphenyl)picolinate dianions $\left(\mathrm{CPA}^{2-}\right){ }^{54}$ Although the crystal structure of these compounds was reported in the $C 2 / c$ space group, this could be converted to $I 2 / a$ by the choice of a conventional unit cell $^{59}$ with parameters similar to 1 . The lanthanoid coordination sphere is analogous to that described for $\mathbf{1}$, and $\mathrm{CPA}^{2-}$ ligands adopt the same coordination mode to form an equivalent $2 \mathrm{D}$ rhombus grid layer. Even more, these layers are assembled into $3 \mathrm{D}$ networks via similar $\mathrm{H}$-bonding and $\pi-\pi$ stacking interactions. As expected, the size of the channels in 1 along its longest direction is notably higher in comparison with this family of compounds $(7.278 \AA \times 19.161 \AA$ for the $\mathrm{Eu}$ complex), due to the presence of the ethynylene spacer. However, when countercations are removed, the "SQUEEZE" option of PLATON ${ }^{60}$ indicates an empty volume of the anionic framework of $558.8 \AA^{3}$ per unit cell for $\left[\left(\mathrm{CH}_{3}\right)_{2} \mathrm{NH}_{2}\right]$ $\left[\mathrm{Eu}\left(\mathrm{H}_{2} \mathrm{O}\right)_{2}(\mathrm{CPA})_{2}\right]$, corresponding to $20 \%$ of the total crystal volume. In compound 1, a significantly lower value of $442.4 \AA^{3}$, corresponding to a percent volume of $14 \%$, is obtained indicating a more compact structure despite the presence of two additional carbon atoms in the ligand.

Compound 2 crystallizes in the orthorhombic $P n a 2_{1}$ space group (Table 1), and its asymmetric unit contains an $\mathrm{Eu}^{3+}$ cation, two crystallographically independent $\mathbf{L}_{2}{ }^{2-}$ anions, one dimethylammonium cation, and two crystallization solvent molecules (water and acetic acid). The $\mathrm{Eu}^{3+}$ cation is located in a general position and exhibits a nine-coordinated tricapped trigonal prismatic (TTP) structure as determined by continuous shape measure (CShM) calculations (Table S4 presents the CShM values for all the possible ninecoordinated-polyhedra, with a minimum CShM value of 3.882 for a tricapped trigonal prism.) Figure 3 shows the coordination sphere of the lanthanoid complex, with four picolinate subunits coordinating in a bidentate fashion, the ninth position being occupied by a bridging carboxylate oxygen atom (Eu1-O5: 2.363(6) A). As in compound 1, Eu-O bond distances (mean value: $2.376(6) \AA$ ) are shorter than $\mathrm{Eu}-\mathrm{N}$ (mean value: $2.650(7) \AA$ ). Thus, the nitrogen atoms N2, N3, and N4 define the capping positions of the tricapped trigonal prism, the two triangular faces being defined by O3O6N2 and $\mathrm{O} 1 \mathrm{O} 5 \mathrm{O} 7$ atoms, respectively. The angle between the trigonal faces is $175.50^{\circ}$, close to the parallel arrangement expected for a TTP structure.

There are two independent bispicolinate $\mathbf{L}_{2}{ }^{2-}$ ligands $\left({ }^{\mathrm{A}} \mathbf{L}_{2}{ }^{2-}\right.$ and ${ }^{B} \mathbf{L}_{2}{ }^{2-}$ ) that adopt different coordination modes. Dianion ${ }^{\mathrm{A}} \mathbf{L}_{2}{ }^{2-}$ employs the two picolinate chelating subunits (N3O6 and N4O7) in coordination: one of them (N3O6) acts as a

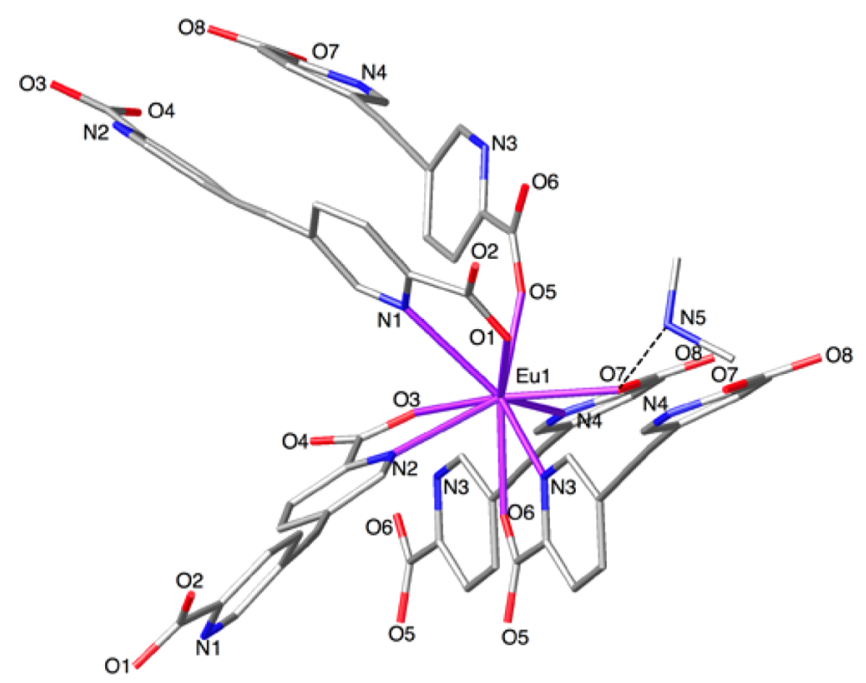

Figure 3. Stick plot of the $\mathrm{Eu}^{3+}$ coordination environment in $\mathbf{2}$.

tridentate ligand in a $(\mathrm{N}, \mathrm{O}) ; \mathrm{O}$ mode, connecting two lanthanoid metal ions by anti, anti-carboxylate (O5O6) bridges. This yields zigzag chains running parallel to the $c$ axis, with a relatively short intrachain distance between adjacent $\mathrm{Eu}^{3+}$ cations of 6.6891(7) $\AA$ (Figure S4). The other picolinate subunit $(\mathrm{N} 4 \mathrm{O} 7)$ coordinates in a terminal chelating manner, bridging neighboring chains related by a translation along the $b$ axis. Thus, this first independent ligand defines layers that lie parallel to the $y z$ plane (Figure $4 \mathrm{a}$ ). The layers are further connected by the second dianion ${ }^{\mathrm{B}} \mathrm{L}_{2}{ }^{2-}$ acting as a simple bisbidentate ligand, with the two picolinate anions (N1O1 and N2O3) being bound in a terminal chelating manner to two $\mathrm{Eu}^{3+}$ cations separated by a long metal-metal distance of $12.8369(6) \AA$.

This results in a $3 \mathrm{D}$ anionic lattice showing triangular cavities (Figure 4b). Charge compensation is provided by dimethylammonium cations sitting within the cavities of the structure and interacting by hydrogen bonding with a

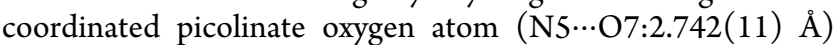

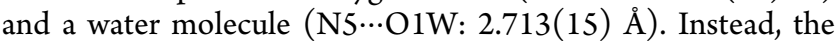
acetic acid molecule forms a short strong $\mathrm{H}$-bond with a noncoordinated oxygen atom (O9... 4 4: 2.549(12) Å).

The two independent ligands adopt markedly different conformations: in ${ }^{\mathrm{A}} \mathbf{L}_{2}{ }^{2-}$, the two pyridine rings are almost perpendicular to each other (the dihedral angle between their mean planes is $100.2(9)^{\circ}$ ), whereas ${ }^{\mathrm{B}} \mathbf{L}_{2}{ }^{2-}$ shows a more planar transoid conformation, with a smaller dihedral angle of 27.2(9) ${ }^{\circ}$. In turn, the distortion of the triple bond is higher for ${ }^{\mathrm{B}} \mathrm{L}_{2}{ }^{2-}$ (-C-C-C- bond angles of $175.5(9)^{\circ}$ and 171.5(9) ${ }^{\circ}$ than for ${ }^{\mathrm{A}} \mathbf{L}_{2}{ }^{2-}(-\mathrm{C}-\mathrm{C}-\mathrm{C}-$ bond angles of $177.5(9)^{\circ}$ and $\left.179.7(9)^{\circ}\right)$. As expected, the picolinate subunits, involved in chelation, are nearly planar, with the highest deviation from planarity being observed for the bridging tridentate picolinate anion (torsion angle between carboxylate and pyridine moieties of $12.3(9)^{\circ}$ ).

Photoluminescent Properties. The electronic absorption spectra of free ligands $\mathrm{H}_{2} \mathrm{~L}_{1}$ and $\mathrm{H}_{2} \mathbf{L}_{2}$ and their $\mathrm{Eu}^{3+}$ complexes were measured in the solid state at room temperature (Figure S5). The UV absorption spectra of both complexes show an intense absorption band at about 250-255 $\mathrm{nm}$ and a second absorption band at about 331-334 nm with the same intensity. These features are almost identical to those observed for the free ligands and are attributed to $\pi \rightarrow \pi^{*}$ and 
a)

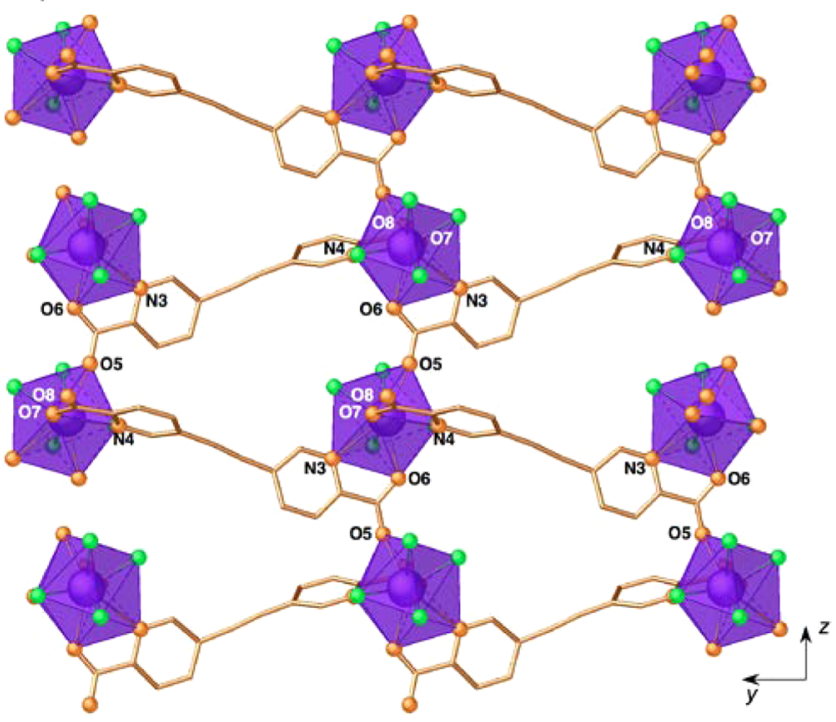

b)

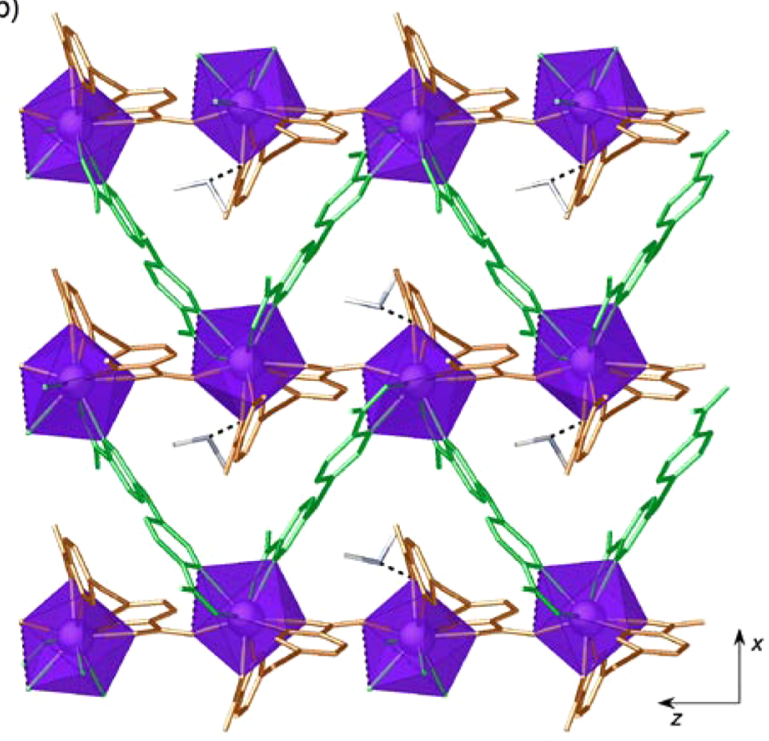

Figure 4. (a) View of the crystal structure of 2 along the $x$ direction showing the layers defined by dianion ${ }^{\mathrm{A}} \mathrm{L}_{2}{ }^{2-}$. (b) Projection of the crystal structure of $\mathbf{2}$ onto the $x z$ plane, showing the zigzag chains defined by dianion ${ }^{\mathrm{B}} \mathbf{L}_{2}{ }^{2-}$ and the presence of triangular voids in the $3 \mathrm{D}$ structure. $\mathrm{H}$ atoms have been omitted for clarity.

$n \rightarrow \pi^{*}$ electronic transitions of the pyridine and benzoate rings. The similarity observed between these patterns indicates that absorption takes place on the ligand rather than directly at the metal center.

The photoluminescence properties of suspensions of compounds $\left[\left(\mathrm{CH}_{3}\right)_{2} \mathrm{NH}_{2}\right]\left[\mathrm{Eu}\left(\mathrm{H}_{2} \mathrm{O}\right)_{2}\left(\mathrm{~L}_{1}\right)_{2}\right]$ (1) and $\left[\left(\mathrm{CH}_{3}\right)_{2} \mathrm{NH}_{2}\right]\left[\mathrm{Eu}\left(\mathbf{L}_{2}\right)_{2}\right] \cdot \mathrm{H}_{2} \mathrm{O} \cdot \mathrm{CH}_{3} \mathrm{COOH}$ (2) and ligands $\mathrm{H}_{2} \mathbf{L}_{1}$ and $\mathrm{H}_{2} \mathbf{L}_{2}$ were investigated in water at room temperature (Figure 5). After UV excitation around $350 \mathrm{~nm}$, the free ligands exhibit an intense emission between 410 and $450 \mathrm{~nm}$, which is attributed to $\pi^{*} \rightarrow \pi$ and $\pi^{*} \rightarrow n$ electronic transitions. Under excitation of complexes $\mathbf{1}$ and $\mathbf{2}$ in similar conditions, the typical red emission of the $\mathrm{Eu}^{3+}$ ion is observed, with emission peaks attributed to transitions between ${ }^{5} D_{0}$ and ${ }^{7} F_{J}$ levels $(J=0,1,2,3,4)$ (Table 2). ${ }^{61}$
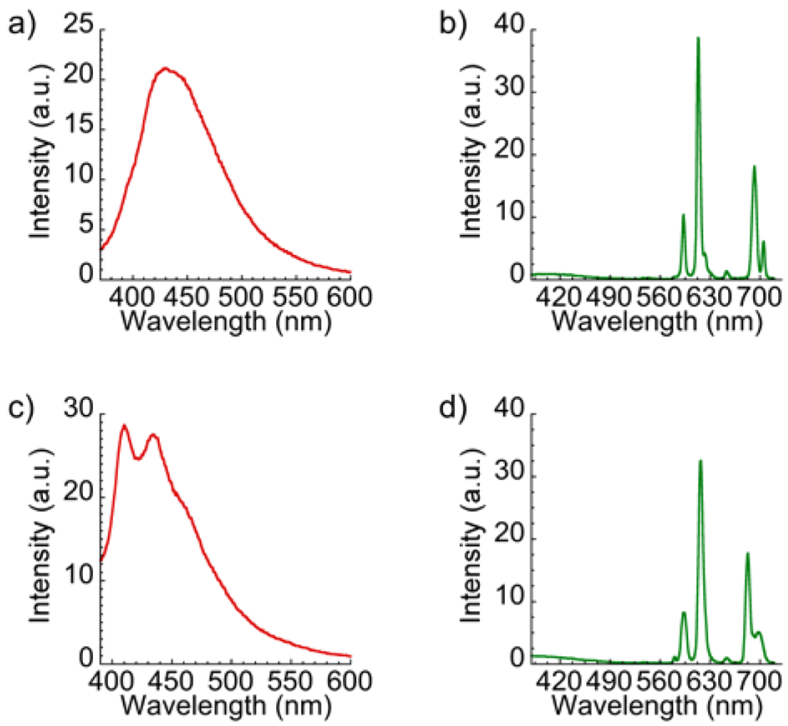

Figure 5. Emission spectra of ligands $\mathrm{H}_{2} \mathbf{L}_{1}\left(\mathrm{a}, \lambda_{\text {exc }}=350 \mathrm{~nm}\right), \mathrm{H}_{2} \mathbf{L}_{2}$ $\left(\mathrm{c}, \lambda_{\mathrm{exc}}=356 \mathrm{~nm}\right)$, and $\mathrm{Eu}^{3+}$ compounds $\mathbf{1}\left(\mathrm{b}, \lambda_{\mathrm{exc}}=344 \mathrm{~nm}\right)$ and $\mathbf{2}$ $\left(\mathrm{d}, \lambda_{\mathrm{exc}}=340 \mathrm{~nm}\right)$.

Table 2. Luminescence Data for Complexes 1 and $2^{a}$

$\begin{array}{ccc}1 \lambda_{\mathrm{em}}(\mathrm{nm}) & \mathbf{2} \lambda_{\mathrm{em}}(\mathrm{nm}) & \text { assignment } \\ 578 & 580 & { }^{5} D_{0} \rightarrow{ }^{7} F_{0} \\ 593 & 592 & { }^{5} D_{0} \rightarrow{ }^{7} F_{1} \\ 614 & 615 & { }^{5} D_{0} \rightarrow{ }^{7} F_{2} \\ 653 & 653 & { }^{5} D_{0} \rightarrow{ }^{7} F_{3} \\ 705 & 690-696 & { }^{5} D_{0} \rightarrow{ }^{7} F_{4}\end{array}$

${ }^{a}$ Peaks at 693 and $680 \mathrm{~nm}$ are attributed to the second harmonic of the laser for complexes $\mathbf{1}$ and $\mathbf{2}$, respectively.

In both complexes, the emission spectrum is dominated by the most intense band at $615 \mathrm{~nm}$ ascribed to ${ }^{5} D_{0} \rightarrow{ }^{7} F_{2}$ transition, which is responsible for the strong red emission. In fact, the intensity ratio of the ${ }^{5} D_{0} \rightarrow{ }^{7} F_{2}$ transition and the ${ }^{5} D_{0}$ $\rightarrow{ }^{7} F_{1}$ transition gives an indication about the symmetry of the first coordination environment of the $\mathrm{Eu}(\mathrm{III})$ ions and has a value of 3.6 for $\mathbf{1}$ and 3.8 for 2 . These values, together with the very low intensity of the ${ }^{5} D_{0} \rightarrow{ }^{7} F_{0}$ transition band, suggest a non-centrosymmetric environment for the metal center. ${ }^{61}$ The values of this ratio are very similar to those obtained for previous europium(III) complexes. For instance, [EuL(HL)$\left.\mathrm{H}_{2} \mathrm{O}\right] \cdot 6 \mathrm{H}_{2} \mathrm{O}$ (being $\mathrm{H}_{2} \mathrm{~L}$ bis(5-(pyridine-2-yl)-1,2,4-triazol-3$\mathrm{yl})$ methane ligand) presents a ratio of $3.4 .^{62}$

It is worth noting that there is a negligible contribution below $500 \mathrm{~nm}$ coming from the ligand in the emission spectrum of complexes 1 and 2 . Therefore, both ligands have proven to be suitable for absorbing light efficiently and transferring this energy to the europium cations with high efficiency. In fact, the excitation spectra of both complexes (Figure S6) monitored within the $\mathrm{Eu}^{3+}$ most intense transition $\left({ }^{5} D_{0} \rightarrow{ }^{7} F_{2}\right)$ are dominated by a broad band from 310 to 390 $\mathrm{nm}$ and from 220 to $375 \mathrm{~nm}$, respectively, corresponding to intraligand transitions. There is also a weak signal at $395 \mathrm{~nm}$ attributed to a transition between the ${ }^{7} F_{0}$ and excited states of $\mathrm{Eu}^{3+}$. The very low relative intensity of this line compared with that of the ligand-based broad band suggests a more efficient ligand-sensitization process than direct intra- $4 \mathrm{f}^{6}$ excitation. 
Luminescence decay curves of $\mathbf{1}$ and $\mathbf{2}$ in the solid state were measured at room temperature by monitoring the time dependence of the strongest ${ }^{5} D_{0} \rightarrow{ }^{7} F_{2}$ emission (Figure 6).

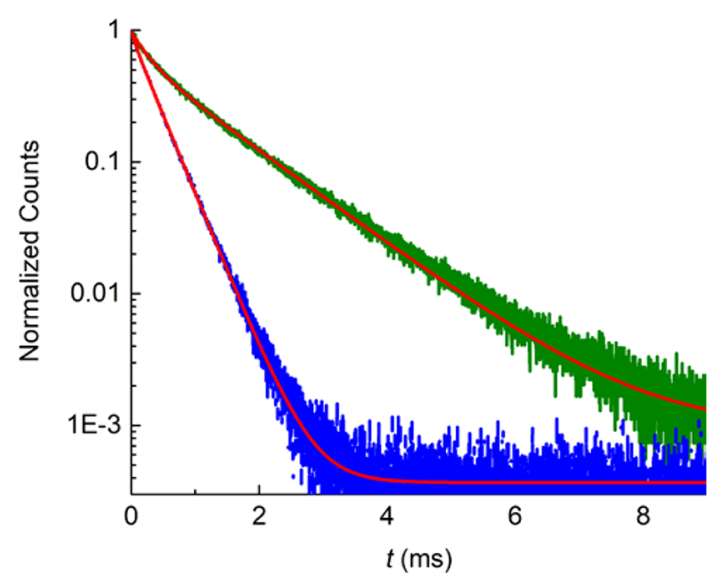

Figure 6. Luminescence decay curves of $\mathbf{1}$ (blue) and $\mathbf{2}$ (green) $\left(\lambda_{\mathrm{em}}\right.$ $=614 \mathrm{~nm}$ ). Best-fit data to a biexponential function are shown in red. The samples were excited with a $375 \mathrm{~nm}$ laser at a frequency of $20 \mathrm{~Hz}$.

In both cases, the decrease in the number of excited fluorophores following optical excitation with a short light pulse was successfully fitted using a biexponential function (eq 1 ), suggesting the existence of two different pathways for luminescence decay:

$$
I=A_{1} \mathrm{e}^{-t / \tau_{1}}+A_{2} \mathrm{e}^{-t / \tau_{2}}
$$

where $\tau_{i}$ is the lifetime and $A_{i}$ is the pre-exponential factor that allows quantitative assignment of the relative contribution of each component. The best-fit data for compound 1 yielded $\tau_{1}$ $=84 \mu \mathrm{s}$ and $\tau_{2}=367 \mu \mathrm{s}$, with $A_{1}=0.0953$ and $A_{2}=0.8848$, and a $\chi^{2}$ value of 0.999 . An average lifetime $\tau_{\mathrm{av}}=360 \mu \mathrm{s}$ was calculated by the following expression: ${ }^{63}$

$$
\tau_{\mathrm{av}}=\frac{A_{1} \tau_{1}^{2}+A_{2} \tau_{2}^{2}}{A_{1} \tau_{1}+A_{2} \tau_{2}}
$$

Instead, for compound 2, values of $\tau_{1}=274 \mu \mathrm{s}$ and $\tau_{2}=$ $1222 \mu \mathrm{s}$, with $A_{1}=0.3514$ and $A_{2}=0.6258\left(\chi^{2}=0.999\right)$, were obtained. This corresponds to an average lifetime $\tau_{\mathrm{av}}=1116$ $\mu \mathrm{s}$. Luminescence lifetimes on the micro- to millisecond time scale are typical for $\mathrm{f}-\mathrm{f}$ transitions that involve long-lived excited states, and the values obtained for $\mathbf{1}$ and $\mathbf{2}$ are within this range (Table S5) ${ }^{64-68}$ However, 2 shows clearly higher lifetime values than 1 . This can be explained taking into account that 1 presents two $\mathrm{H}_{2} \mathrm{O}$ molecules in the coordination sphere of the $\mathrm{Eu}^{3+}$ cation. It is well-known that nonradiative decay of the excited states of $\mathrm{Eu}^{3+}$ takes place via vibronic coupling with the vibrational modes of $\mathrm{O}-\mathrm{H}$ bonds of coordinated water molecules, leading to a significant reduction of excited state lifetimes. ${ }^{69}$ This is why the luminescence of lanthanoid-based complexes is markedly influenced by the denticity of the ligand, polydentate ligands being useful for increasing the stability of the complexes and allowing the metal center to be protected from solvent molecules.

Photoluminescence quantum yields (PLQY) were measured by placing the samples into an integrating sphere. Values of $23 \%$ and $29 \%$ were obtained for complexes $\mathbf{1}$ and 2 , respectively. These values are typical for $\mathrm{Eu}^{3+}$ coordination polymers (Table S5). The slightly higher value obtained for $\mathbf{2}$ parallels the lifetime measurements and is due to the lack of coordinating water molecules. This behavior has been well documented for many hydrated europium diketonate complexes. ${ }^{70}$ Nonetheless, a recent report on $\left[\mathrm{EuKL}_{4}\left(\mathrm{H}_{2} \mathrm{O}\right)_{2}\right] \cdot \mathrm{H}_{2} \mathrm{O}$ (being $\mathrm{HL}=7$-chloro-1-cyclopropyl-6-fluoro-4-oxo-1,4-dihydroquinoline-3-carboxylic acid) presents an ultrahigh quantum yield value of $92 \%$, which is much higher than for most lanthanoid complexes. ${ }^{71}$

Luminescence Sensing of Solvent Molecules. The luminescence sensing response of both europium derivatives for different solvent molecules was studied at room temperature. The as-synthesized crystals $(1 \mathrm{mg})$ were ground and suspended in different solvents $(1 \mathrm{~mL})$, and the corresponding emission spectra were recorded (Figure S7). The intensity of the strongest peak that corresponds to the ${ }^{5} D_{0} \rightarrow{ }^{7} F_{2}$ transition was taken for comparison. The luminescence signal of $\mathbf{1}$ (Figure 7a) was enhanced by solvents like $\mathrm{MeOH}, \mathrm{EtOH}$,

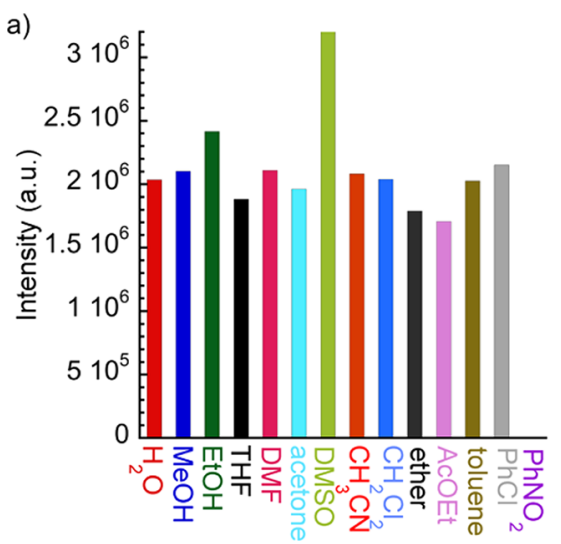

b)

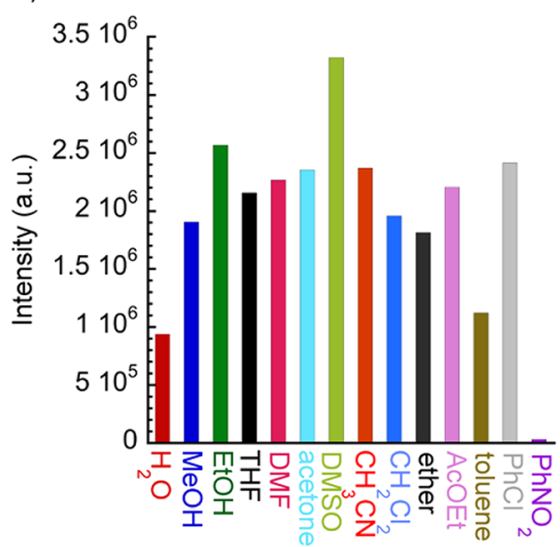

Figure 7. Bar plots of emissive intensities (peak height at $\lambda=614 \mathrm{~nm}$ ) for $1\left(\mathrm{a}, \lambda_{\mathrm{exc}}=344 \mathrm{~nm}\right)$ and $2\left(\mathrm{~b}, \lambda_{\mathrm{exc}}=340 \mathrm{~nm}\right)$ dispersed in different solvents.

$\mathrm{CH}_{3} \mathrm{CN}, \mathrm{DMF}$, and DMSO, presenting in the last case a huge increase of $72 \%\left(I(D M S O) / I\left(\mathrm{H}_{2} \mathrm{O}\right) \approx 1.72\right)$. For other solvent molecules, the emission intensity was slightly reduced. Remarkably, nitrobenzene $\left(\mathrm{PhNO}_{2}\right)$ could effectively quench the luminescence of $\mathbf{1}$. For $\mathbf{2}$, a general enhancement of the luminescence signal was observed when a solvent different to water was used, except for $\mathrm{PhNO}_{2}$, that exhibited an almost complete luminescence quenching (Figure 7b). Again, a remarkable luminescence increase $\left(I(\mathrm{DMSO}) / I\left(\mathrm{H}_{2} \mathrm{O}\right) \approx\right.$ 3.6) was observed in DMSO suspensions. 
In order to investigate these luminescence enhancement and quenching effects (Figure S8), powder X-ray diffraction (PXRD) measurements of both $\mathrm{Eu}^{3+}$ coordination polymers were carried out after the corresponding solid samples were suspended in DMSO and $\mathrm{PhNO}_{2}$. A perfect agreement between these diffractograms and those corresponding to the as-synthesized materials was obtained, indicating that their crystal structures are retained after interaction with these solvent molecules.

An increase of emission intensity after soaking in DMSO has been previously noted in $\mathrm{Eu}^{3+}$ complexes and ascribed to energy transfer from DMSO to the antenna ligand. ${ }^{72}$ However, in this case DMSO molecules do not absorb energy at the excitation wavelengths used (340 and $344 \mathrm{~nm}$, Figure S9), discarding this hypothesis. Thus, a possible explanation for this fact relies on the exchange of inner-sphere coordinating water molecules or hydrogen-bonded water molecules by DMSO on the surface of the particles, which would preserve their crystal integrity. In this way, nonradiative decay of the excited states through vibronic coupling with the vibrational modes of $\mathrm{O}-\mathrm{H}$ bonds would be reduced, with the corresponding enhancement in the europium emission.

Regarding nitrobenzene quenching, the disruption of the crystal structure can also be excluded since the diffraction patterns remain unaltered after dispersing the solids in this solvent. The absorption spectrum of $\mathrm{PhNO}_{2}$ was compared to the emission spectra of $\mathbf{1}$ and $\mathbf{2}$ (Figure S9). The lack of spectral overlap between absorption and emission patterns discards a resonance energy transfer process between $\mathrm{Eu}^{3+}$ ions and $\mathrm{PhNO}_{2}$. Nevertheless, there is a spectral overlap between the absorption spectrum of $\mathrm{PhNO}_{2}$ and the emission of ligands $\mathrm{H}_{2} \mathbf{L}_{1}$ and $\mathrm{H}_{2} \mathbf{L}_{2}$, indicating that a Förster resonance energy transfer (FRET) might be at the origin of the quenching process. However, since $\mathrm{PhNO}_{2}$ can absorb energy at the excitation wavelength used in these experiments ( 344 and 340 $\mathrm{nm}$, respectively), a competitive absorption mechanism cannot be excluded. Energy competition between Eu complexes and nitroaromatic compounds has been already noted as a possible mechanism of luminescence quenching. ${ }^{73,74}$

The above results suggest that $\mathbf{1}$ and $\mathbf{2}$ could be used as specific luminescent sensors for nitroaromatic molecules. Thus, titration experiments with $\mathrm{PhNO}_{2}(0.1 \mathrm{M}$ in EtOH$)$ were undertaken on aqueous suspensions of $\mathbf{1}$ and 2 . Both complexes exhibited a very similar gradual decrease of the luminescence intensity as the concentration of $\mathrm{PhNO}_{2}$ was increased (Figure 8a,b). The luminescence intensity versus $\mathrm{PhNO}_{2}$ concentration plot was fitted by using the well-known Stern-Volmer equation (insets Figure $8 \mathrm{a}, \mathrm{b}):^{95,76}$

$$
\frac{I_{0}}{I}=1+K_{\mathrm{SV}}\left[\mathrm{PhNO}_{2}\right]
$$

Stern-Volmer plots display a linear variation at a low concentration of quencher, while they present a quadratic dependence at higher concentrations. This indicates the existence of two different relaxation mechanisms, static and dynamic quenching. ${ }^{76}$ The calculated Stern-Volmer quenching constants $\left(K_{\mathrm{SV}}\right)$ were $1.50 \times 10^{2} \mathrm{M}^{-1}$ and $1.60 \times 10^{2} \mathrm{M}^{-1}$ for 1 and 2, respectively, indicating that both compounds show a moderate nitrobenzene sensing ability in comparison to other $\mathrm{Eu}(\mathrm{III})$ luminescent sensors (Table S2). Moreover, the limit of $\mathrm{PhNO}_{2}$ detection (LOD) was calculated based on the following equation:
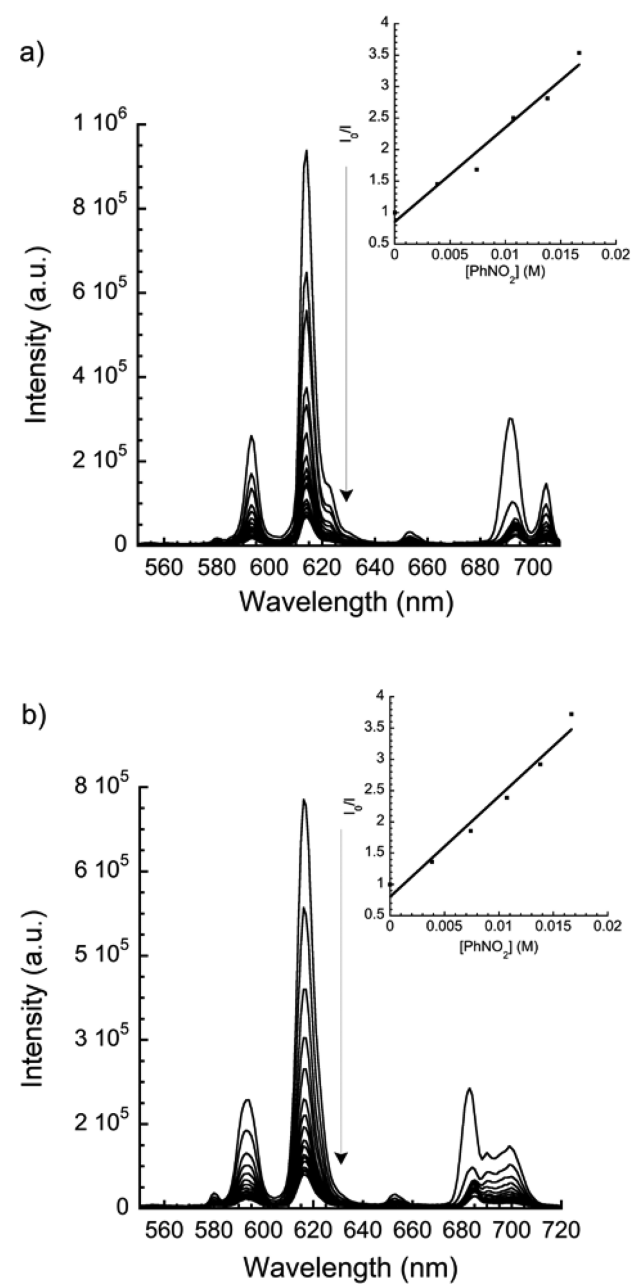

Figure 8. Emission spectra of $\mathbf{1}\left(\mathrm{a}, \lambda_{\mathrm{exc}}=344 \mathrm{~nm}\right)$ and $\mathbf{2}\left(\mathrm{b}, \lambda_{\mathrm{exc}}=340\right.$ $\mathrm{nm}$ ) upon addition of different volumes of $\mathrm{PhNO}_{2}(0.1 \mathrm{M}$ in EtOH). Insets show Stern-Volmer plots for $\mathbf{1}$ (a) and $\mathbf{2}$ (b) in the low $\left[\mathrm{PhNO}_{2}\right]$ region, together with data fits to the Stern-Volmer equation.

$$
\mathrm{LOD}=\frac{3 \delta}{s}
$$

where $s$ is the slope of the plot of luminescence intensity against $\mathrm{PhNO}_{2}$ concentration in the linear region (Figure S10) and $\delta$ is the standard deviation for 10 repeated luminescence measurements of the blank solution. The results show detection limits of $2.05 \times 10^{-5} \mathrm{M}$ and $3.03 \times 10^{-5} \mathrm{M}$ for 1 and 2 , respectively. These values compare well with those reported for similar Eu(III) complexes (Table S2).

Luminescence Sensing of Metal Ions. Coordination polymers 1 and $2(1 \mathrm{mg})$ were dispersed in $1 \mathrm{~mL}$ aqueous solutions containing $0.01 \mathrm{M}$ of $\mathrm{MCl}_{n}$ or $\mathrm{M}\left(\mathrm{NO}_{3}\right)_{n}$ metal salts $\left(\mathrm{M}=\mathrm{Li}^{+}, \mathrm{Na}^{+}, \mathrm{K}^{+}, \mathrm{Mg}^{2+}, \mathrm{Ca}^{2+}, \mathrm{Mn}^{2+}, \mathrm{Fe}^{3+}, \mathrm{Co}^{2+}, \mathrm{Ni}^{2+}, \mathrm{Cu}^{2+}\right.$, $\mathrm{Zn}^{2+}, \mathrm{Cd}^{2+}, \mathrm{Al}^{3+}, \mathrm{In}^{3+}, \mathrm{Pb}^{2+}, \mathrm{Sm}^{3+}, \mathrm{Tb}^{3+}$, and $\left.\mathrm{Dy}^{3+}\right)$, and then the luminescence spectra were recorded (Figure S11). Again, in order to analyze the data, the strongest peak, corresponding to the ${ }^{5} D_{0} \rightarrow{ }^{7} F_{2}$ transition, was taken for comparison. For $\mathbf{1}$, all metal ions exhibited luminescence quenching effects (Figure 9a). Noteworthy is the fact that $\mathrm{Fe}^{3+}$ and $\mathrm{Pb}^{2+}$ ions could almost completely quench its luminescence, $\mathrm{Fe}^{3+}$ being more effective than $\mathrm{Pb}^{2+}$ ions (up to $80 \%$ and $72 \%$, respectively). On the other hand, metals like $\mathrm{Li}^{+}, \mathrm{Na}^{+}, \mathrm{Mg}^{2+}$, and $\mathrm{Ca}^{2+}$ increased the emission intensity of 2 , the remaining 


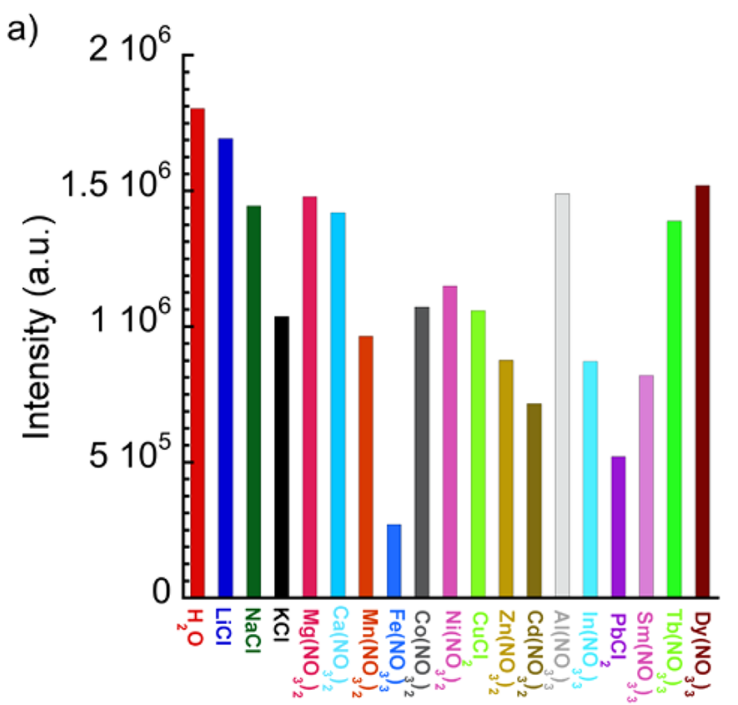

b)

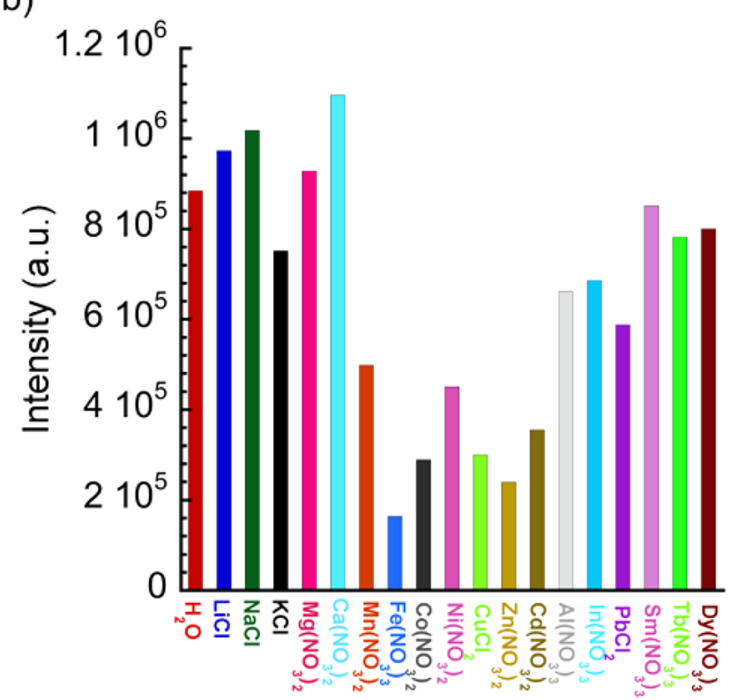

Figure 9. Bar plots of emissive intensities (corresponding to the ${ }^{5} D_{0}$ $\rightarrow{ }^{7} F_{2}$ transition) for $1\left(\mathrm{a}, \lambda_{\text {exc }}=344 \mathrm{~nm}\right)$ and $\mathbf{2}\left(\mathrm{b}, \lambda_{\text {exc }}=340 \mathrm{~nm}\right)$ in $0.01 \mathrm{M}$ aqueous solutions of different metal ions.

metal ions resulting in different degrees of luminescence quenching (Figure $9 \mathrm{~b}$ ). $\mathrm{Fe}^{3+}, \mathrm{Cd}^{2+}$, and $\mathrm{Zn}^{2+}$ metal ions stand out with quenching efficiencies of 82,68 , and $69 \%$, respectively. These results are consistent with the fact that $\mathrm{Pb}^{2+}$ ions present higher affinity for oxygen donor ligands than for nitrogen-based ligands. That means that $\mathrm{Pb}^{2+}$ ions exhibit a greater competition for $\mathbf{L}_{1}$ ligand coordination with respect to $\mathbf{L}_{2}$, the former containing an additional carboxylate functional group. $\mathrm{Ln}^{3+}, \mathrm{Mg}^{2+}$, and $\mathrm{Ca}^{2+}$ cations present also higher affinity for oxygen donor ligands. Therefore, the decrease in the emission intensity is higher for $\mathbf{1}$ in these cases as well. Instead, transition metal cations like $\mathrm{Co}^{2+}, \mathrm{Ni}^{2+}, \mathrm{Cu}^{2+}, \mathrm{Zn}^{2+}$, and $\mathrm{Cd}^{2+}$ exhibit a higher affinity for nitrogen donor ligands, and this is in agreement with the stronger quenching effect observed for 2. In general, 2, containing the bis(picolinate) ligand, shows a better stability in these metal-sensing experiments than 1 .

PXRD measurements were conducted (Figure S12) in order to check the stability of the crystalline frameworks after interaction with $\mathrm{Fe}^{3+}$ and $\mathrm{Pb}^{2+}$ cations. PXRD patterns of $\mathbf{1}$ and 2 suspended in aqueous solutions of $\mathrm{Fe}^{3+}$ cations are consistent with the original frameworks, whereas the pattern of 1 suspended in an aqueous solution of $\mathrm{Pb}^{2+}$ cations is completely different. This indicates that collapse of the original network takes place, possibly resulting from the interaction between $\mathrm{Pb}^{2+}$ cations and the uncoordinated carboxylate groups in the channel. Energy-dispersive X-ray (EDX) microanalysis carried out on a scanning electron microscope (SEM) showed that this sample contains both $\mathrm{Pb}^{2+}$ and $\mathrm{Eu}^{3+}$ ions, with a $\mathrm{Pb}^{2+} / \mathrm{Eu}^{3+}$ ratio of 1.3. The same analysis for the compounds soaked in aqueous solutions of $\mathrm{Fe}^{3+}$ ions indicates that these cations are not present in the composition of the soaked materials. Therefore, the collapse of the framework of 1 induces the variation of the luminescence intensity after immersion in a $\mathrm{Pb}^{2+}$ aqueous solution, but this can be ruled out for $\mathrm{Fe}^{3+}$ sensing. In order to get more insight into the iron(III) quenching mechanism, electronic absorption spectra were recorded for aqueous solutions of the different metal ions and compared to the emission spectra of $\mathbf{1}$ and 2, together with those of corresponding ligands (Figure S13). The lack of overlap between the absorption spectra of the different metallic ions and the emission spectra of the complexes discards a resonance energy transfer mechanism for luminescence quenching. Nonetheless, there is a considerable overlap between the absorption spectrum of $\mathrm{Fe}^{3+}$ ions and the emission spectra of ligands $\mathbf{H}_{2} \mathbf{L}_{1}$ and $\mathbf{H}_{2} \mathbf{L}_{2}$. Energy transfer from excited levels of the ligand to the $\mathrm{Fe}^{3+}$ ions could be a possible quenching mechanism. On the other hand, the wide absorption band of $\mathrm{Fe}^{3+}$ ions ranging from 430 to $260 \mathrm{~nm}$ covers the wavelength used for excitation of 1 and 2 (344 and $340 \mathrm{~nm}$, respectively), while other metal ions such as $\mathrm{Pb}^{2+}$ have no absorption in this range. Therefore, competitive absorption by $\mathrm{Fe}^{3+}$ ions could also account for the quenching process.

Selectivity and sensitivity of both complexes toward $\mathrm{Fe}^{3+}$ detection were also studied. First, competitive experiments containing $\mathrm{Fe}^{3+}$ and different metal ions showed that quenching of the emission is due only to the presence of the ferric species (Figure S14). A suspension of each complex (1 $\mathrm{mg}$ in $1 \mathrm{~mL} \mathrm{H}_{2} \mathrm{O}$ ) was then titrated with $\mathrm{Fe}^{3+}$ aqueous solutions of concentrations $25 \mathrm{mM}$ and $50 \mathrm{mM}$, respectively, for 1 and 2. The luminescence of the $\mathrm{Eu}^{3+}$ polymers was gradually quenched (Figure 10). Further, in order to discard dilution effects, the emission of both suspensions prepared in an equivalent volume of water was registered (Figure S15). There is a clear difference between the intensities recorded in the presence and in the absence of $\mathrm{Fe}^{3+}$ ions, verifying that a quenching process is present.

The quenching efficiency was quantitatively evaluated using the Stern-Volmer eq 3, in this case $\mathrm{Fe}^{3+}$ being the quencher species. The Stern-Volmer plots present again an upward bending at a high concentration of quencher, characteristic of the existence of static and dynamic quenching mechanisms. ${ }^{76}$ From the fit of the experimental data at low $\mathrm{Fe}^{3+}$ concentrations (from 0.19 to $3.77 \mathrm{mM}$ and from 0 to 6.9 $\mathrm{mM}$, respectively, for $\mathbf{1}$ and 2 ) to the Stern-Volmer equation (insets of Figure 10), $K_{S V}$ values of $4.71 \times 10^{2} \mathrm{M}^{-1}$ and $7.06 \times$ $10^{2} \mathrm{M}^{-1}$ are obtained for 1 and 2 , respectively. These values are comparable to those obtained by other previously reported $\mathrm{Eu}^{3+}$ coordination polymers $\left(10^{3}-10^{4} \mathrm{M}^{-1}\right.$, Table S1). ${ }^{55}$

Furthermore, the limit of detection (LOD) was calculated from $3 \delta / \mathrm{s}$ (eq 4 , where $\delta$ is the standard deviation of 10 consecutive blank measurements, and $s$ is the slope of luminescence intensity vs $\left[\mathrm{Fe}^{3+}\right]$ plot in the linear region), giving a value of $5.82 \times 10^{-6} \mathrm{M}$ and $3.16 \times 10^{-6} \mathrm{M}$ for 1 and 2 , 

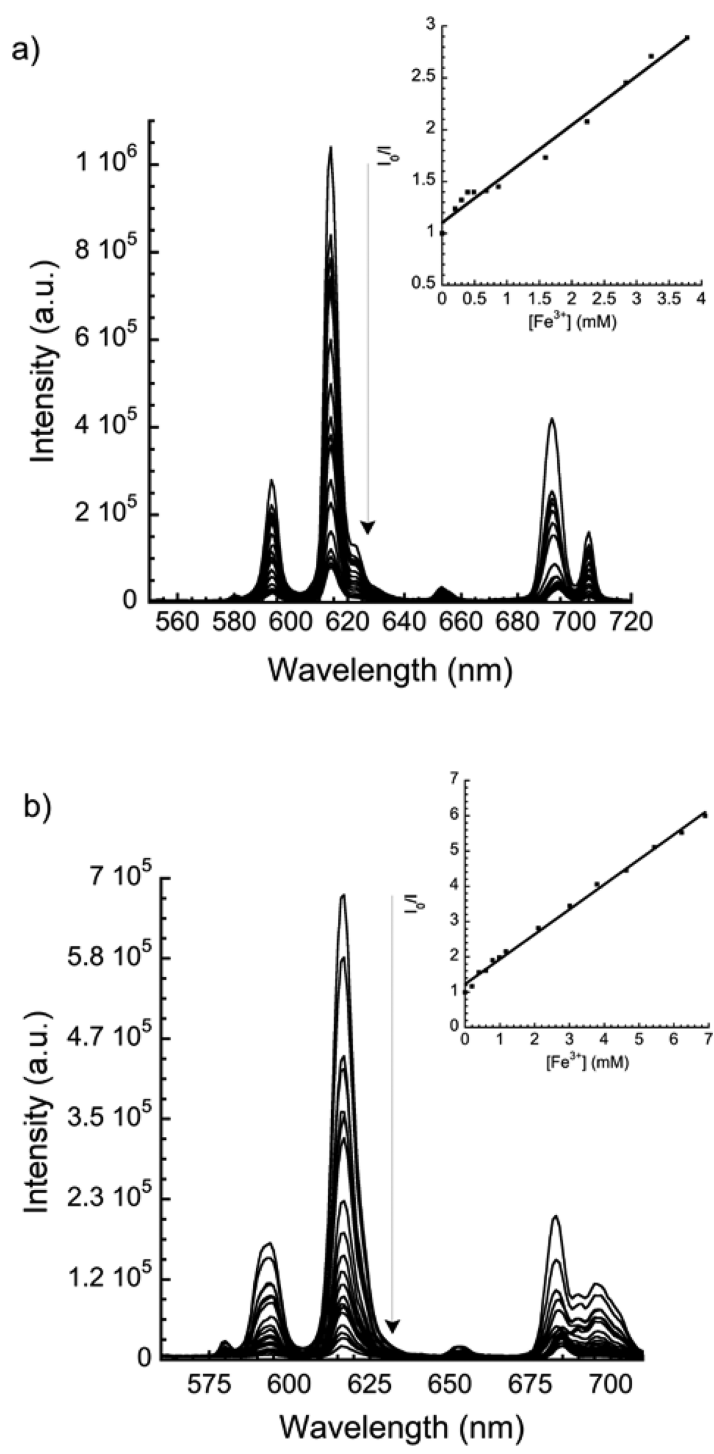

Figure 10. Emission spectra of $1\left(\mathrm{a}, \lambda_{\mathrm{exc}}=344 \mathrm{~nm}\right)$ and $2\left(\mathrm{~b}, \lambda_{\mathrm{exc}}=\right.$ $340 \mathrm{~nm}$ ) upon addition of different volumes of a $\mathrm{Fe}^{3+}$ aqueous solution ( $25 \mathrm{mM}$ for 1 and $50 \mathrm{mM}$ for 2 ). Insets show the respective Stern-Volmer plots corresponding to the low $\left[\mathrm{Fe}^{3+}\right]$ region, together with a data fit to the Stern-Volmer equation.

respectively (Figure S16). Both values are very similar and within the range reported for other sensors based on $\mathrm{Eu}^{3+}$ coordination polymers (Table S1) but still far from the $10^{-7} \mathrm{M}$ value obtained for $\left[\left(\mathrm{CH}_{3}\right)_{2} \mathrm{NH}_{2}\right]\left[\mathrm{Eu}(\mathrm{CPA})_{2}\left(\mathrm{H}_{2} \mathrm{O}\right)_{2}\right]\left(\mathrm{CPA}^{2-}\right.$ = 5-(4-carboxyphenyl)picolinate dianion $)$, one of the highest reported to date. ${ }^{54}$

Luminescence studies as a function of $\mathrm{pH}$ were carried out for both complexes in water suspensions. The emission was registered at different $\mathrm{pH}$ values ranging from 1 to 14 . The $\mathrm{pH}$ of each aqueous solution was adjusted by the addition of $\mathrm{HCl}$ or $\mathrm{NaOH}$ solutions. For 1, it was found (Figure 11a) that Eubased emission is almost constant in the $\mathrm{pH}$ range comprised between 3 and 12, whereas at extreme acid or basic $\mathrm{pH}$ values, there is a complete disappearance of the luminescence, together with the onset of a molecular fluorescence emission $\left(\lambda_{\max }=396-432 \mathrm{~nm}\right)$, which is attributed to the decomposition of the complex and release of the free ligand in its protonated or fully deprotonated forms. ${ }^{62}$ The remarkable stability of 1 was demonstrated after soaking the coordination

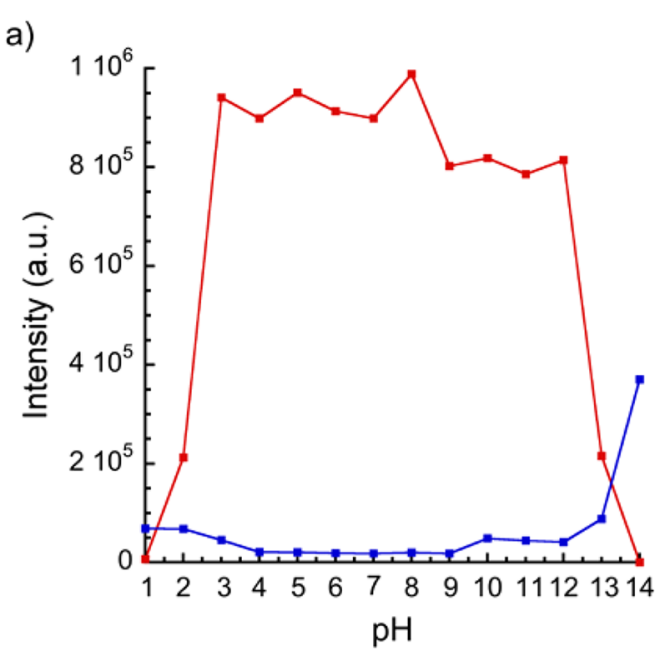

b)

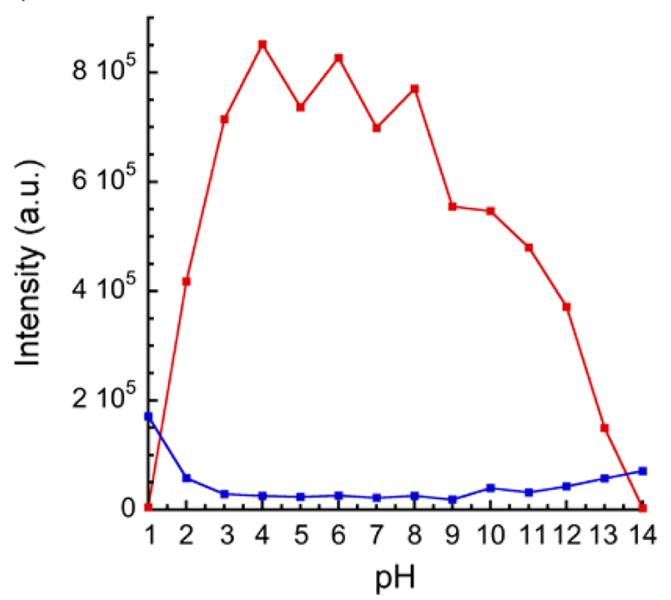

Figure 11. $\mathrm{pH}$ dependence of the emission intensity of 1 (a) and 2 (b) (red dots: $\mathrm{Eu}^{3+}$ emission at $614 \mathrm{~nm}$; blue dots: ligand-based emission at $396-432 \mathrm{~nm}$ for 1 and $400-376 \mathrm{~nm}$ for 2).

polymer in an aqueous solution at $\mathrm{pH}=12$ for $12 \mathrm{~h}$ (Figure S17). The powder X-ray diffractogram of the solid obtained was identical to that of the pristine material. This is in contrast with previous reports showing a lack of stability in most cases. ${ }^{71}$ There are only two previous reports showing a similar robustness in these conditions, ${ }^{77,78}$ but these compounds exhibit higher LOD in comparison with 1 . Instead, 2 displays the strong emissive properties in a shorter $\mathrm{pH}$ range $(3<\mathrm{pH}<$ 8) (Figure 11b). Again, a molecular-based emission (at 400$376 \mathrm{~nm}$ ) is observed at $\mathrm{pH}=1,13$, and 14, which is ascribed to the release of free ligand at extreme $\mathrm{pH}$ values. PXRD experiments (Figures S18-S19) confirm the collapse of the crystal structure at $\mathrm{pH}=1$ and $\mathrm{pH}=14$ for both compounds. The lower stability of 2 outside the $3-8 \mathrm{pH}$ range was also confirmed by the presence of minor diffraction peaks in the Xray diffractogram.

\section{CONCLUSIONS}

To summarize, two water-stable luminescent $\mathrm{Eu}^{3+}$ coordination polymers $\mathbf{1}$ and $\mathbf{2}$ have been synthesized from ethynylenebridged ditopic picolinate ligands by the hydrothermal method. Suspensions of these compounds in water exhibited a strong $\mathrm{Eu}^{3+}$ emission under UV light irradiation, characteristic of effective ligand-to-metal energy transfer (antenna 
effect). Luminescence could be quenched by nitrobenzene, with limits of detection of $2.05 \times 10^{-5} \mathrm{M}$ and $3.03 \times 10^{-5}$ for 1 and 2 , respectively. These coordination polymers were also able to act as luminescent sensors for $\mathrm{Fe}^{3+}$ cations, with limits of detection in the micromolar region $\left(5.82 \times 10^{-6} \mathrm{M}\right.$ and 3.16 $\times 10^{-6}$ for 1 and 2 , respectively). Noteworthy is the very high stability of these coordination polymers under extreme $\mathrm{pH}$ conditions.

\section{ASSOCIATED CONTENT}

\section{SI Supporting Information}

The Supporting Information is available free of charge at https://pubs.acs.org/doi/10.1021/acs.inorgchem.1c01229.

Figures S1 (PXRD measurements), S2 (TGA), S3-S4 (structure plots), S5 (absorption spectra), S6 (excitation spectra), S7 (emission spectra in different solvents), S8 (PXRD in different solvents), S9 (spectral overlap with different solvents), $\mathrm{S} 10$ (luminescence vs $\left[\mathrm{PhNO}_{2}\right]$ plot), S11 (emission spectra in the presence of different metal ions), S12 (PXRD in the presence of different metal ions), S13 (spectral overlap in the presence of different metal ions), S14 (selective $\mathrm{Fe}^{3+}$ sensing experiments), S15 (dilution experiments), S16 (luminescence vs $\left[\mathrm{Fe}^{3+}\right] \mathrm{plot}$ ), $\mathrm{S} 17$ (stability of 1 at $\mathrm{pH}=12$ ), S18-S19 (PXRD of $\mathbf{1}$ and $\mathbf{2}$ at different $\mathrm{pH}$ values), and Tables S1-S2 (reported Stern-Volmer constants and LOD values for detection of $\mathrm{Fe}^{3+}$ cations and nitrobenzene, respectively), S3-S4 (continuous shape measures for $\mathbf{1}$ and 2, respectively) and S5 (reported quantum yield and lifetime values for selected $\mathrm{Eu}^{3+}$ complexes) (PDF)

\section{Accession Codes}

CCDC 2068840 and 2068875 contain the supplementary crystallographic data for this paper. These data can be obtained free of charge via www.ccdc.cam.ac.uk/data request/cif, or by emailingdata_request@ccdc.cam.ac.uk, or by contacting The Cambridge Crystallographic Data Centre, 12 Union Road, Cambridge CB2 1EZ, UK; fax: +44 1223336033.

\section{AUTHOR INFORMATION}

\section{Corresponding Author}

Francisco M. Romero - Instituto de Ciencia Molecular, Universitat de Vatencia, 46071 Valencia, Spain; ○ orcid.org/0000-0002-1936-0781; Email: fmrm@uv.es

\section{Authors}

Verónica Jornet-Mollá - Instituto de Ciencia Molecular, Universitat de Valencia, 46071 Valencia, Spain

Chris Dreessen - Instituto de Ciencia Molecular, Universitat de Valencia, 46071 Vatencia, Spain; 이이.org/00000001-7444-6900

Complete contact information is available at:

https://pubs.acs.org/10.1021/acs.inorgchem.1c01229

\section{Author Contributions}

C.D. did the time-resolved photoluminescence measurements. V.J.M. performed all other experiments, including the synthesis and solid state characterization of the compounds. F.M.R. supervised the work and revised the manuscript.

\section{Notes}

The authors declare no competing financial interest.

\section{ACKNOWLEDGMENTS}

We thank Laura Martínez-Sarti for the photoluminescence quantum yield measurements. We acknowledge financial support from the Spanish MINECO (Project CTQ201787201-P AEI/FEDER, UE) and Generalitat Valenciana (Prometeo/2019/076 project). V.J-M. thanks the MICINN for a FPU fellowship (FPU15/02804). C.D. acknowledges financial support from "la Caixa" Foundation (ID 100010434, code LCF/BQ/DI19/11730020).

\section{REFERENCES}

(1) Tranchemontagne, D. J.; Mendoza-Cortés, J. L.; O’Keeffe, M.; Yaghi, O. M. Secondary building units, nets and bonding in the chemistry of metal-organic frameworks. Chem. Soc. Rev. 2009, 38, 1257-1283.

(2) He, Y.; Li, B.; O’Keeffe, M.; Chen, B. Multifunctional metalorganic frameworks constructed from meta-benzenedicarboxylate units. Chem. Soc. Rev. 2014, 43, 5618-5656.

(3) Li, M.; Li, D.; O’Keeffe, M.; Yaghi, O. M. Topological Analysis of Metal-Organic Frameworks with Polytopic Linkers and/or Multiple Building Units and the Minimal Transitivity Principle. Chem. Rev. 2014, 114, 1343-1370.

(4) Lin, Z. J.; Lü, J.; Hong, M.; Cao, R. Metal-organic frameworks based on flexible ligands (FL-MOFs): structures and applications. Chem. Soc. Rev. 2014, 43, 5867-5895.

(5) Stock, N.; Biswas, S. Synthesis of Metal-Organic Frameworks (MOFs): Routes to Various MOF Topologies, Morphologies, and Composites. Chem. Rev. 2012, 112, 933-969.

(6) Mon, M.; Lloret, F.; Ferrando-Soria, J.; Martí-Gastaldo, C.; Armentano, D.; Pardo, E. Selective and Efficient Removal of Mercury from Aqueous Media with the Highly Flexible Arms of a BioMOF. Angew. Chem., Int. Ed. 2016, 55, 11167-11172.

(7) Mason, J. A.; Oktawiec, J.; Taylor, M. K.; Hudson, M. R.; Rodriguez, J.; Bachman, J. E.; Gonzalez, M. I.; Cervellino, A.; Guagliardi, A.; Brown, C. M.; Llewellyn, P. L.; Masciocchi, N.; Long, J. R. Methane storage in flexible metal-organic frameworks with intrinsic thermal management. Nature 2015, 527, 357-361.

(8) Zhu, J.; Usov, P. M.; Xu, W.; Celis-Salazar, P.; Lin, S.; Kessinger, M. C.; Landaverde-Alvarado, C.; Cai, M.; May, A. M.; Slebodnick, C.; Zhu, D.; Senanayake, S. D.; Morris, A. J. A New Class of MetalCyclam-Based Zirconium Metal-Organic Frameworks for $\mathrm{CO}_{2}$ Adsorption and Chemical Fixation. J. Am. Chem. Soc. 2018, 140, 993-1003.

(9) Li, P.; He, Y.; Zhao, Y.; Weng, L.; Wang, H.; Krishna, R.; Wu, H.; Zhou, W.; O'Keeffe, M.; Han, Y.; Chen, B. A Rod-Packing Microporous Hydrogen-Bonded Organic Framework for Highly Selective Separation of $\mathrm{C}_{2} \mathrm{H}_{2} / \mathrm{CO}_{2}$ at Room Temperature. Angew. Chem., Int. Ed. 2015, 54, 574-577.

(10) Chen, C.-X.; Zheng, S.-P.; Wei, Z.-W.; Cao, C.-C.; Wang, H.-P.; Wang, D.; Jiang, J.-J.; Fenske, D.; Su, C.-Y. A Robust Metal-Organic Framework Combining Open Metal Sites and Polar Groups for Methane Purification and $\mathrm{CO}_{2} /$ Fluorocarbon Capture. Chem. - Eur. J. 2017, 23, 4060-4064.

(11) He, C.; Liu, D.; Lin, W. Nanomedicine Applications of Hybrid Nanomaterials Built from Metal-Ligand Coordination Bonds: Nanoscale Metal-Organic Frameworks and Nanoscale Coordination Polymers. Chem. Rev. 2015, 115, 11079-11108.

(12) Rocha, J.; Carlos, L. D.; Almeida Paz, F. A.; Ananias, D. Luminescent multifunctional lanthanoids-based metal-organic frameworks. Chem. Soc. Rev. 2011, 40, 926-940.

(13) Xu, H.; Cao, C.-S.; Kang, X.-M.; Zhao, B. Lanthanoid-based metal-organic frameworks as luminescent probes. Dalton Trans. 2016, 45, 18003-18017.

(14) Yan, B. Lanthanoid-Functionalized Metal-Organic Framework Hybrid Systems To Create Multiple Luminescent Centers for Chemical Sensing. Acc. Chem. Res. 2017, 50, 2789-2798. 
(15) Dhakshinamoorthy, A.; Asiri, A. M.; García, H. Metal-Organic Framework (MOF) Compounds: Photocatalysts for Redox Reactions and Solar Fuel Production. Angew. Chem., Int. Ed. 2016, 55, 54145445.

(16) Gao, W.-Y.; Wu, H.; Leng, K.; Sun, Y.; Ma, S. Inserting $\mathrm{CO}_{2}$ into Aryl $\mathrm{C}-\mathrm{H}$ Bonds of Metal-Organic Frameworks: $\mathrm{CO}_{2}$ Utilization for Direct Heterogeneous $\mathrm{C}-\mathrm{H}$ Activation. Angew. Chem., Int. Ed. 2016, 55, 5472-5476.

(17) Huang, N.; Wang, K.; Drake, H.; Cai, P.; Pang, J.; Li, J.; Che, S.; Huang, L.; Wang, Q.; Zhou, H.-C. Tailor-Made Pyrazolide-Based Metal-Organic Frameworks for Selective Catalysis. J. Am. Chem. Soc. 2018, 140, 6383-6390.

(18) Cui, Y.; Chen, B.; Qian, G. Lanthanoid metal-organic frameworks for luminescent sensing and light-emitting applications. Coord. Chem. Rev. 2014, 273-274, 76-86.

(19) Fan, K.; Bao, S.-S.; Nie, W.-X.; Liao, C.-H.; Zheng, L.-M. Iridium(III)-Based Metal-Organic Frameworks as Multiresponsive Luminescent Sensors for $\mathrm{Fe}^{3+}, \mathrm{Cr}_{2} \mathrm{O}_{7}{ }^{2-}$, and $\mathrm{ATP}^{2-}$ in Aqueous Media. Inorg. Chem. 2018, 57, 1079-1089.

(20) Mahata, P.; Mondal, S. K.; Singha, D. K.; Majee, P. Luminescent rare-earth-based MOFs as optical sensors. Dalton Trans. 2017, 46, 301-328.

(21) Bhattacharyya, S.; Chakraborty, A.; Jayaramulu, K.; Hazra, A.; Maji, T. K. A bimodal anionic MOF: turn-off sensing of $\mathrm{Cu}^{\mathrm{II}}$ and specific sensitization of $\mathrm{Eu}^{\text {III. }}$. Chem. Commun. 2014, 50, 1356713570 .

(22) Luo, T.-Y.; Das, P.; White, D. L.; Liu, C.; Star, A.; Rosi, N. L. Luminescence "Turn-On" Detection of Gossypol Using $\mathrm{Ln}^{3+}$-Based Metal-Organic Frameworks and $\mathrm{Ln}^{3+}$ Salts. J. Am. Chem. Soc. 2020, 142, 2897-2904.

(23) Zhao, M.; Yao, Z.-Q.; Xu, Y.-L.; Chang, Z.; Bu, X.-H. Guest dependent structure and acetone sensing properties of a $2 \mathrm{D} \mathrm{E \textrm {Eu } ^ { 3 + }}$ coordination polymer. RSC Adv. 2017, 7, 2258-2263.

(24) Yang, L.-Z.; Wang, J.; Kirillov, A. M.; Dou, W.; Xu, C.; Fang, R.; Xu, C.-L.; Liu, W.-S. $2 \mathrm{D}$ lanthanoid MOFs driven by a rigid 3,5bis(3-carboxy-phenyl)pyridine building block: solvothermal syntheses, structural features, and photoluminescence and sensing properties. CrystEngComm 2016, 18, 6425-6436.

(25) Dang, S.; Ma, E.; Sun, Z.-M.; Zhang, H. A layer-structured EuMOF as a highly selective fluorescent probe for $\mathrm{Fe}^{3+}$ detection through a cation-exchange approach. J. Mater. Chem. 2012, 22, $16920-16926$.

(26) Li, G.-P.; Liu, G.; Li, Y.-Z.; Hou, L.; Wang, Y.-Y.; Zhu, Z. Uncommon Pyrazoyl-Carboxyl Bifunctional Ligand-Based Microporous Lanthanoid Systems: Sorption and Luminescent Sensing Properties. Inorg. Chem. 2016, 55, 3952-3959.

(27) Wen, G.-X.; Wu, Y.-P.; Dong, W.-W.; Zhao, J.; Li, D.-S.; Zhang, J. An Ultrastable Europium(III)-Organic Framework with the Capacity of Discriminating $\mathrm{Fe}^{2+} / \mathrm{Fe}^{3+}$ Ions in Various Solutions. Inorg. Chem. 2016, 55, 10114-10117.

(28) Yan, W.; Zhang, C.; Chen, S.; Han, L.; Zheng, H. Two Lanthanoid Metal-Organic Frameworks as Remarkably Selective and Sensitive Bifunctional Luminescence Sensor for Metal Ions and Small Organic Molecules. ACS Appl. Mater. Interfaces 2017, 9, 1629-1634.

(29) Zheng, M.; Tan, H.; Xie, Z.; Zhang, L.; Jing, X.; Sun, Z. Fast Response and High Sensitivity Europium Metal Organic Framework Fluorescent Probe with Chelating Terpyridine Sites for $\mathrm{Fe}^{3+}$. ACS Appl. Mater. Interfaces 2013, 5, 1078-1083.

(30) Liang, Y.-T.; Yang, G.-P.; Liu, B.; Yan, Y.-T.; Xi, Z.-P.; Wang, Y.-Y. Four super water-stable lanthanoid-organic frameworks with active uncoordinated carboxylic and pyridyl groups for selective luminescence sensing of $\mathrm{Fe}^{3+}$. Dalton Trans. 2015, 44, 13325-13330.

(31) Li, L.; Chen, Q.; Niu, Z.; Zhou, X.; Yang, T.; Huang, W. Lanthanoid metal-organic frameworks assembled from a fluorenebased ligand: selective sensing of $\mathrm{Pb}^{2+}$ and $\mathrm{Fe}^{3+}$ ions. J. Mater. Chem. C 2016, 4, 1900-1905.

(32) Yi, P.; Huang, H.; Peng, Y.; Liu, D.; Zhong, C. A series of europium-based metal organic frameworks with tuned intrinsic luminescence properties and detection capacities. RSC $A d v$. 2016, 6, 111934-111941.

(33) Liu, W.; Huang, X.; Xu, C.; Chen, C.; Yang, L.; Dou, W.; Chen, W.; Yang, H.; Liu, W. A Multi-responsive Regenerable EuropiumOrganic Framework Luminescent Sensor for $\mathrm{Fe}^{3+}, \mathrm{Cr}^{\mathrm{VI}}$ Anions, and Picric Acid. Chem. - Eur. J. 2016, 22, 18769-18776.

(34) Singha, D. K.; Majee, P.; Mondal, S. K.; Mahata, P. A EuDoped Y-Based Luminescent Metal-Organic Framework as a Highly Efficient Sensor for Nitroaromatic Explosives. Eur. J. Inorg. Chem. 2015, 2015, 1390-1397.

(35) Yuan, S.; Feng, L.; Wang, K.; Pang, J.; Bosch, M.; Lollar, C.; Sun, Y.; Qin, J.; Yang, X.; Zhang, P.; Wang, Q.; Zou, L.; Zhang, Y.; Zhang, L.; Fang, Y.; Li, J.; Zhou, H.-C. Stable Metal-Organic Frameworks: Design, Synthesis, and Applications. Adv. Mater. 2018, 30, 1704303.

(36) Caskey, S. R.; Wong-Foy, A. G.; Matzger, A. J. Dramatic Tuning of Carbon Dioxide Uptake via Metal Substitution in a Coordination Polymer with Cylindrical Pores. J. Am. Chem. Soc. 2008, 130, 10870-10871.

(37) Bloch, E. D.; Murray, L. J.; Queen, W. L.; Chavan, S.; Maximoff, S. N.; Bigi, J. P.; Krishna, R.; Peterson, V. K.; Grandjean, F.; Long, G. J.; Smit, B.; Bordiga, S.; Brown, C. M.; Long, J. R. Selective Binding of $\mathrm{O}_{2}$ over $\mathrm{N}_{2}$ in a Redox-Active Metal-Organic Framework with Open Iron(II) Coordination Sites. J. Am. Chem. Soc. 2011, 133, 14814-14822.

(38) Kapelewski, M. T.; Geier, S. J.; Hudson, M. R.; Stück, D.; Mason, J. A.; Nelson, J. N.; Xiao, D. J.; Hulvey, Z.; Gilmour, E.; FitzGerald, S. A.; Head-Gordon, M.; Brown, C. M.; Long, J. R. $\mathrm{M}_{2}(m-$ dobdc) $(\mathrm{M}=\mathrm{Mg}, \mathrm{Mn}, \mathrm{Fe}, \mathrm{Co}, \mathrm{Ni})$ Metal-Organic Frameworks Exhibiting Increased Charge Density and Enhanced $\mathrm{H}_{2}$ Binding at the Open Metal Sites. J. Am. Chem. Soc. 2014, 136, 12119-12129.

(39) Hmadeh, M.; Lu, Z.; Liu, Z.; Gándara, F.; Furukawa, H.; Wan, S.; Augustyn, V.; Chang, R.; Liao, L.; Zhou, F.; Perre, E.; Ozolins, V.; Suenaga, K.; Duan, X.; Dunn, B.; Yamamto, Y.; Terasaki, O.; Yaghi, O. M. New Porous Crystals of Extended Metal-Catecholates. Chem. Mater. 2012, 24, 3511-3513.

(40) Cui, J.; Wong, Y.-L.; Zeller, M.; Hunter, A. D.; Xu, Z. Pd Uptake and $\mathrm{H}_{2} \mathrm{~S}$ Sensing by an Amphoteric Metal-Organic Framework with a Soft Core and Rigid Side Arms. Angew. Chem. Int. Ed. 2014, 53, 14438-14442.

(41) Marshall, R. J.; Griffin, S. L.; Wilson, C.; Forgan, R. S. Stereoselective Halogenation of Integral Unsaturated C-C Bonds in Chemically and Mechanically Robust Zr and Hf MOFs. Chem. - Eur. J. 2016, 22, 4870-4877.

(42) Kodanko, J. J.; Xu, D.; Song, D.; Lippard, S. J. Iron Substitution for Sodium in a Carboxylate-Bridged, Heterodinuclear Sodium-Iron Complex. J. Am. Chem. Soc. 2005, 127, 16004-16005.

(43) Park, B. G.; Pink, M.; Lee, D. Fluorogenic N,O-chelates built on a $C_{2}$-symmetric aryleneethynylene platform: Spectroscopic and structural consequences of conformational preorganization and ligand denticity. J. Organomet. Chem. 2011, 696, 4039-4045.

(44) Severance, R. C.; Rountree, E. S.; Smith, M. D.; zur Loye, H.-C. Ligand-based luminescence in lead-containing complexes: The effect of conjugated organic ligands on fluorescence. Solid State Sci. 2012, 14, 1512-1519.

(45) Matt, B.; Xiang, X.; Kaledin, A. L.; Han, N.; Moussa, J.; Amouri, H.; Alves, S.; Hill, C. L.; Lian, T.; Musaev, D. G.; Izzet, G.; Proust, A. Long lived charge separation in iridium(III)-photosensitized polyoxometalates: synthesis, photophysical and computational studies of organometallic-redox tunable oxide assemblies. Chem. Sci. 2013, 4, 1737-1745.

(46) Bünzli, J.-C. G.; Piguet, C. Taking advantage of luminescent lanthanoid ions. Chem. Soc. Rev. 2005, 34, 1048-1077.

(47) Lamture, J. B.; Zhou, Z. H.; Kumar, A. S.; Wensel, T. G. Luminescence Properties of Terbium(III) Complexes with 4Substituted Dipicolinic Acid Analogs. Inorg. Chem. 1995, 34, 864869. 
(48) Jornet-Mollá, V.; Romero, F. M. Synthesis of rigid ethynylbridged polytopic picolinate ligands for MOF applications. Tetrahedron Lett. 2015, 56, 6120-6122.

(49) CrysAlisPro, v38.46, Oxford Diffraction Ltd., 2017.

(50) Farrugia, L. J. WinGX suite for small-molecule single-crystal crystallography. J. Appl. Crystallogr. 1999, 32, 837-838.

(51) Sheldrick, G. M. Crystal structure refinement with SHELXL. Acta Crystallogr., Sect. C: Struct. Chem. 2015, C71, 3-8.

(52) Sudik, A. C.; Millward, A. R.; Ockwig, N. W.; Côté, A. P.; Kim, J.; Yaghi, O. M. Design, Synthesis, Structure, and Gas $\left(\mathrm{N}_{2}, \mathrm{Ar}, \mathrm{CO}_{2}\right.$, $\mathrm{CH}_{4}$, and $\mathrm{H}_{2}$ ) Sorption Properties of Porous Metal-Organic Tetrahedral and Heterocuboidal Polyhedra. J. Am. Chem. Soc. 2005, 127, 7110-7118.

(53) Han, M.-L.; Xu, G.-W.; Li, D.-S.; Azofra, L. M.; Zhao, J.; Chen, B.; Sun, C. A Terbium-Organic Framework Material for Highly Sensitive Sensing of $\mathrm{Fe}^{3+}$ in Aqueous and Biological Systems: Experimental Studies and Theoretical Analysis. ChemistrySelect 2016, 1, 3555-3561.

(54) Wu, Y.-P.; Xu, G.-W.; Dong, W.-W.; Zhao, J.; Li, D.-S.; Zhang, J.; Bu, X. Anionic Lanthanoid MOFs as a Platform for Iron-Selective Sensing, Systematic Color Tuning, and Efficient Nanoparticle Catalysis. Inorg. Chem. 2017, 56, 1402-1411.

(55) Casanova, D.; Alemany, P.; Bofill, J. M.; Alvarez, S. Shape and Symmetry of Heptacoordinate Transition-Metal Complexes: Structural Trends. Chem. - Eur. J. 2003, 9, 1281-1285.

(56) Alvarez, S.; Alemany, P.; Casanova, D.; Cirera, J.; Llunell, M.; Avnir, D. Shape maps and polyhedral interconversion paths in transition metal chemistry. Coord. Chem. Rev. 2005, 249, 1693-1708.

(57) Llunell, M.; Casanova, D.; Cirera, J.; Bofill, J. M.; Alemany, P.; Alvarez, S. SHAPE, Version 2.1; Barcelona, 2013.

(58) Alvarez, S.; Avnir, D.; Llunell, M.; Pinsky, M. Continuous symmetry maps and shape classification. The case of six-coordinated metal compounds. New J. Chem. 2002, 26, 996-1009.

(59) Spek, A. L. Single structure validation with the program PLATON. J. Appl. Crystallogr. 2003, 36, 7-13.

(60) Spek, A. L. PLATON SQUEEZE: a tool for the calculation of the disordered solvent contribution to the calculated structure factors. Acta Crystallogr., Sect. C: Struct. Chem. 2015, C71, 9-18.

(61) Vicentini, G.; Zinner, L. B.; Zukerman-Schpector, J.; Zinner, K. Luminescence and structure of europium compounds. Coord. Chem. Rev. 2000, 196, 353-382.

(62) Gusev, A. N.; Hasegawa, M.; Nishchymenko, G. A.; Shul'gin, V. F.; Meshkova, S. B.; Doga, P.; Linert, W. Ln(III) complexes of a bis(5-(pyridine-2-yl)-1,2,4-triazol-3-yl)methaneligand: synthesis, structure and fluorescent properties. Dalton Trans. 2013, 42, 69366943.

(63) Li, P.; Wang, Z.; Yang, Z.; Guo, Q. Tunable blue-green emission phosphor $\mathrm{Ca}_{2} \mathrm{PO}_{4} \mathrm{Cl}: \mathrm{Ce}^{3+}, \mathrm{Tb}^{3+}$ : Luminescence and energy transfer. Opt. Commun. 2014, 332, 83-88.

(64) Latva, M.; Takalo, H.; Mukkala, V.-M.; Matachescu, C.; Rodríguez-Ubis, J. C.; Kankare, J. Correlation between the lowest triplet state energy level of the ligand and lanthanoid(III) luminescence quantum yield. J. Lumin. 1997, 75, 149-169.

(65) Faschinger, F.; Ertl, M.; Zimmermann, M.; Horner, A.; Himmelsbach, M.; Schöfberger, W.; Knör, G.; Gruber, H. J. Stable Europium(III) Complexes with Short Linkers for Site-Specific Labeling of Biomolecules. ChemistryOpen 2017, 6, 721-732.

(66) Shi, M.; Ding, C.; Dong, J.; Wang, H.; Tian, Y.; Hu, Z. A novel europium(iii) complex with versatility in excitation ranging from infrared to ultraviolet. Phys. Chem. Chem. Phys. 2009, 11, 5119-5123.

(67) Dasari, S.; Patra, A. K. Luminescent europium and terbium complexes of dipyridoquinoxaline and dipyridophenazine ligands as photosensitizing antennae: structures and biological perspectives. Dalton Trans. 2015, 44, 19844-19855.

(68) Biju, S.; Raj, D. B. A.; Reddy, M. L. P.; Kariuki, B. M. Synthesis, Crystal Structure, and Luminescent Properties of Novel $\mathrm{Eu}^{3+}$ Heterocyclic $\beta$-Diketonate Complexes with Bidentate Nitrogen Donors. Inorg. Chem. 2006, 45, 10651-10660.
(69) Khullar, S.; Singh, S.; Das, P.; Mandal, S. K. Luminescent Lanthanoid-Based Probes for the Detection of Nitroaromatic Compounds in Water. ACS Omega 2019, 4, 5283-5292.

(70) de Sá, G. F.; Malta, O. L.; de Mello Donegá, C.; Simas, A. M.; Longo, R. L.; Santa-Cruz, P. A.; da Silva, E. F., Jr. Spectroscopic properties and design of highly luminescent lanthanoid coordination complexes. Coord. Chem. Rev. 2000, 196, 165-195.

(71) Zheng, K.; Liu, Z.; Jiang, Y.; Guo, P.; Li, H.; Zeng, C.; Ng, S. W.; Zhong, S. Ultrahigh luminescence quantum yield lanthanoid coordination polymer as a multifunctional sensor. Dalton Trans. 2018, 47, 17432-17440.

(72) Yang, T. L.; Qin, W. W. Synthesis and luminescence spectral properties of europium(III) and terbium(III) complexes with a new Schiff base ligand N, N', N"-tri-(2,4-dihydroxyl-acetophenone)triaminotriethylamine. Indian J. Chem. 2006, 45A, 2035-2039.

(73) Gao, M. L.; Cao, X.-M.; Zhang, Y.-Y.; Qi, M.-H.; Wang, S.-M.; Liu, L.; Han, Z.-B. A bifunctional luminescent europium-organic framework for highly selective sensing of nitrobenzene and 4aminophenol. RSC Adv. 2017, 7, 45029-45033.

(74) Zhao, S.-N.; Song, X.-Z.; Zhu, M.; Meng, X.; Wu, L.-L.; Song, S.-Y.; Wang, C.; Zhang, H.-J. Highly thermostable lanthanoid metalorganic frameworks exhibiting unique selectivity for nitro explosives. RSC Adv. 2015, 5, 93-98.

(75) Xiao, Y.; Cui, Y.; Zheng, Q.; Xiang, S.; Qian, G.; Chen, B. A microporous luminescent metal-organic framework for highly selective and sensitive sensing of $\mathrm{Cu}^{2+}$ in aqueous solution. Chem. Commun. 2010, 46, 5503-5505.

(76) Cano-Raya, C.; Fernádez Ramos, M. D.; Capitán Vallvey, L. F.; Wolfbeis, O. F.; Schäferling, M. Fluorescence Quenching of the Europium Tetracycline Hydrogen Peroxide Complex by Copper (II) and other Metal Ions. Appl. Spectrosc. 2005, 59, 1209-1216.

(77) Gai, Y.-L.; Guo, Q.; Zhao, X.-Y.; Chen, Y.; Liu, S.; Zhang, Y.; Zhuo, C.-X.; Yao, C.; Xiong, K.-C. Extremely stable europium-organic framework for luminescent sensing of $\mathrm{Cr}_{2} \mathrm{O}_{7}^{2-}$ and $\mathrm{Fe}^{3+}$ in aqueous systems. Dalton Trans. 2018, 47, 12051-12055.

(78) Zhan, Z.; Liang, X.; Zhang, X.; Jia, Y.; Hu, M. A water-stable europium-MOF as a multifunctional luminescent sensor for some trivalent metal ions $\left(\mathrm{Fe}^{3+}, \mathrm{Cr}^{3+}, \mathrm{Al}^{3+}\right), \mathrm{PO}_{4}{ }^{3-}$ ions, and nitroaromatic explosives. Dalton Trans. 2019, 48, 1786-1794. 